\title{
An Evaluation of Kriging Techniques for High Level Radioactive Waste Repository Site Characterization
}

\author{
P. G. Doctor
}

January 1979

Prepared for the U.S. Department of Energy under Contract EY-76-C-06-1830

Pacific Northwest Laboratory Operated for the U.S. Department of Energy by Battelle Memorial Institute 


\title{
NOTICE
}

This report was prepared as an account of work sponsored by the United States Government. Neither the United States nor the Department of Energy, nor any of their employees, nor any of their contractors, subcontractors, or their employees, makes any warranty, express or implied, or assumes any legal liability or responsibility for the accuracy, completeness or usefulness of any information, apparatus, product or process disclosed, or represents that its use would not infringe privately owned rights.

The views, opinions and conclusions contained in this report are those of the contractor and do not necessarily represent those of the United States Government or the United States Department of Energy.

\author{
PACIFIC NORTHWEST LABORATORY \\ operated by \\ BATTELLE \\ for the \\ UNITED STATES DEPARTMENT OF ENERGY \\ Under Contract EY-76-C-06-1830
}
Printed in the United States of America Available from
National Technical Information Service United States Department of Commerce 5285 Port Royal Road
Springfield, Virginia 22151

Price: Printed Copy $\$$. ; Microfiche $\$ 3.00$

NTIS

-Pages Selling Price

$001-025 \quad \$ 4.00$

$026-050 \quad \$ 4.50$

051-075 $\$ 5.25$

076-100 $\$ 6.00$

$101-125 \quad \$ 6.50$

$126-150 \quad \$ 7.25$

$151-175 \quad \$ 8.00$

$176-200 \quad \$ 9.00$

$201-225 \quad \$ 9.25$

$226-250 \quad \$ 99.50$

$251-275 \quad \$ 10.75$

$276-300 \quad \$ 11.00$ 
PNL -2903

UC -70

\section{9}

AN EVALUATION OF KRIGING TECHNIQUES

FOR HIGH LEVEL RADIOACTIVE WASTE

REPOSITORY SITE CHARACTERIZATION

P. G. Doctor

January 1979

Prepared for

the U.S. Department of Energy

under Contract EY-76-C-06-1830

Pacific Northwest Laboratory

Richland, Washington 99352 


\section{Executive Summary}

The purpose of this study is to evaluate kriging, a statistical technique that has potential use in site selection and safety assessment for permanent storage of high-level radioactive waste. The predominant applications have been in mining and meteorology. However, it has been increasingly used in oil exploration, most notably by Shell International Petroleum.

Kriging is a statistical method for estimating functions that describe spatially-distributed phenomena such as groundwater elevation (potential) and depth to basalt. A potential geologic repository must be evaluated from very sparse data. Core samples which provide the most reliable information are intrusive and costly; thus, the objective is to minimize the number of cores taken. The contribution of kriging to this objective is two-fold. First, kriging produces a contour model of the geologic formation of a potential site with an associated measure of uncertainty. This provides a more complete characterization than can be gained from other contouring methods. Secondly, given the existing data, kriging can be used to optimize the selection of additional sampling locations. This feature provides a rationale for sample-location selection and could cut data acquisition costs significantiy.

The most efficient way to evaluate kriging is by experimenting with the techniques on representative data sets. The Hanford Wells data base proved to be the most accessible. llater elevation tends to be a fairly smooth spatially-distributed phenomenon and since the-Hanford Wells water elevation data set is fairly extensive, the September 1973 and January 1975 data were used to gain familiarity with the techniques. The top-of-basalt elevations from the well data base are more characteristic of the type of 
data used to evaluate potential sites: that is, a rougher spatially-distributed phenomenon and fewer data points.

The kriging computations are performed using BLUEPACK, a computer package developed by the Paris School of Mines and installed at the DOELas Vegas computing facility. It is currently being accessed using a DECWRITER terminal over Federal Telecommunications System lines.

The basic criterion for evaluating kriging used in this study is how realistically it contours the water potential and basalt surfaces. The water potential surface is quite well-known; hand-drawn contour maps, based on substantive knowledge in addition to well data, are considered the standard. The kriged contours based on only the well data are quite similar to the hand-drawn contours. The kriging standard errors (measure of uncertainty) provide a quantification of the precision of these contours in various locations of the reservation. They can be used to help select additional data sampling locations.

The basalt surface is much less well-known than the water potential surface. Consequently, existing top-of-basalt contour maps rely very heavily on substantive knowledge. The presence of discontinuities, such as synclines, necessitates a more complex kriging analysis. The kriged contours based on only the well data and the approximate locations of two major syclines showed good agreement with the existing contour maps. The basalt kriging standard errors were much larger than those for the water elevation surface which reflects the more complex spatial structure of the basalt deposits.

The main conclusion of this study is that kriging can be a useful tool in developing realistic contours of the geologic structure of a potential 
repository site. Second, the kriging standard errors provide a quantification of the precision of the contours; this can be useful evidential information for developing a site-selection rationale. Thirdly, insights gained from the kriging analyses can contribute to the substantive knowledge of the geologic or hydrologic phenomenon under study; an example is "the inverse problem" in hydrology, which is the derivation of hydraulic conductivity (an aereal distribution) from groundwater potentiometric (point) measurements. The development of kriging into an effective tool for geologic repository site characterization for the licensing process requires an interdisciplinary environment. An immediate benefit of this environment would be improvements to the kriged groundwater and basalt surface contours presented in this document. More importantly, the interaction of kriging methodology with the traditional deterministic models of geologic phenomena will result in a more defensible repository site characterization; kriging can be used for the statistical evaluation of the physical models, and input from physical models will produce more realistic kriging models. 


\section{ACKNOWLEDGMENT}

I would like to express my appreciation to Maitland Lee; without her programming expertise, there would be no contour plots of the kriging results. 


\section{CONTENTS}

Executive Summary . . . . . . . . . . . . . . . . . . . $i$ i

I. Introduction ...................... 1

A. Introduction ....................... 1

B. Scope of Study . . . . . . . . . . . . . . . . . . 4

II. Kriging... . . . . . . . . . . . . . . . . . 5

A. Overview of Kriging Theory . . . . . . . . . . . . 5

B. Computer Codes ................... . 21

III. Practical Results . . . . . . . . . . . . . . . . . 27

A. Description of Data . . . . . . . . . . . . . . 27

B. Hanford Reservation Groundwater Potential . . . . . . . . 31

C. Hanford Reservation Top-of-Basalt Elevations . . . . . . . 51

IV. Summary and Conclusions . . . . . . . . . . . . . . 62

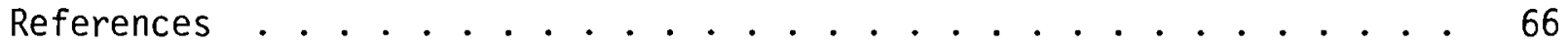

Appendix . . . . . . . . . . . . . . . . . . . . . A-1 


\section{INTRODUCTION}

\section{A. Background}

A proposed solution to the disposal of high level radioactive waste products is to isolate them in permanent underground repositories such as a salt or basalt deposit. The purpose is to keep the waste products contained until they are no longer radiotoxic. For some elements, this will be a long time: up to several million years. Since the primary man-made containment vessels will deteriorate in that time, the geologic structure serving as the repository will have to serve as the ultimate containment vessel.

Before a site is chosen as a permanent waste repository, as much information as possible must be obtained on its geologic structure (shape, dimensions, presence of faults) and chemical composition. The most reliable information on both aspects is provided by core samples. Besides being very costly, cores are intrusive. Therefore, there cannot be a sufficient number of cores taken to adequately characterize the geologic structure without destroying its integrity. There are two approaches to the problem: 1) make inferences on the suitability of the site on very few data points, or 2) make use of less costly and nonintrusive measurement techniques such as seismic. Both approaches are used.

Kriging is a statistical technique that can be useful for both approaches. First, it can derive more information from few data points than conventional methods. Second, it can be used to combine different types of data (seismic, 
core, and qualitative) to produce a more complete characterization of the geologic phenomenon.

By definition, geologic phenomena are spatial phenomena. That means that if the water potential is measured at one point $X$ (see Figure 1), it will agree pretty closely with that measured at point $Y$, and still be related, but less closely, to the water potential measured at point $z$. This presents serious problems for elementary statistics, which assumes that the three measurements are independent, that is, not related. For that reason, many of the methods that have been used to map or contour spatial phenomenon have been deterministic rather than stochastic. Any text on mathematical geology is replete with these types of techniques. Statistical (or stochastic) techniques are receiving more attention because of problems associated with the deterministic techniques. Perhaps the most important is the fact that there is no way to quantify the accuracy of the deterministicaliy-fit surface. More geologic applications, such as repository site characterization, are demanding that type of information. The statistical techniques have the potential to provide that information.

There are two main statistical approaches to spatial estimation: trend surface methodology and kriging. Trend surface methodology is based on a polynomial fitting procedure primarily used in the United States and Britain (Watson (1969)). Kriging is a moving-average technique developed by the French and South Africans (Krige (1966) and Matheron (1971)).

There are problems associated with trend surface techniques. The estimated contours are greatly affected by the location of data points. The kriging estimate of the contours on the other hand, is not as influenced by the location of data points because it uses the correlation structure among the observations. Trend surface analysis can produce 


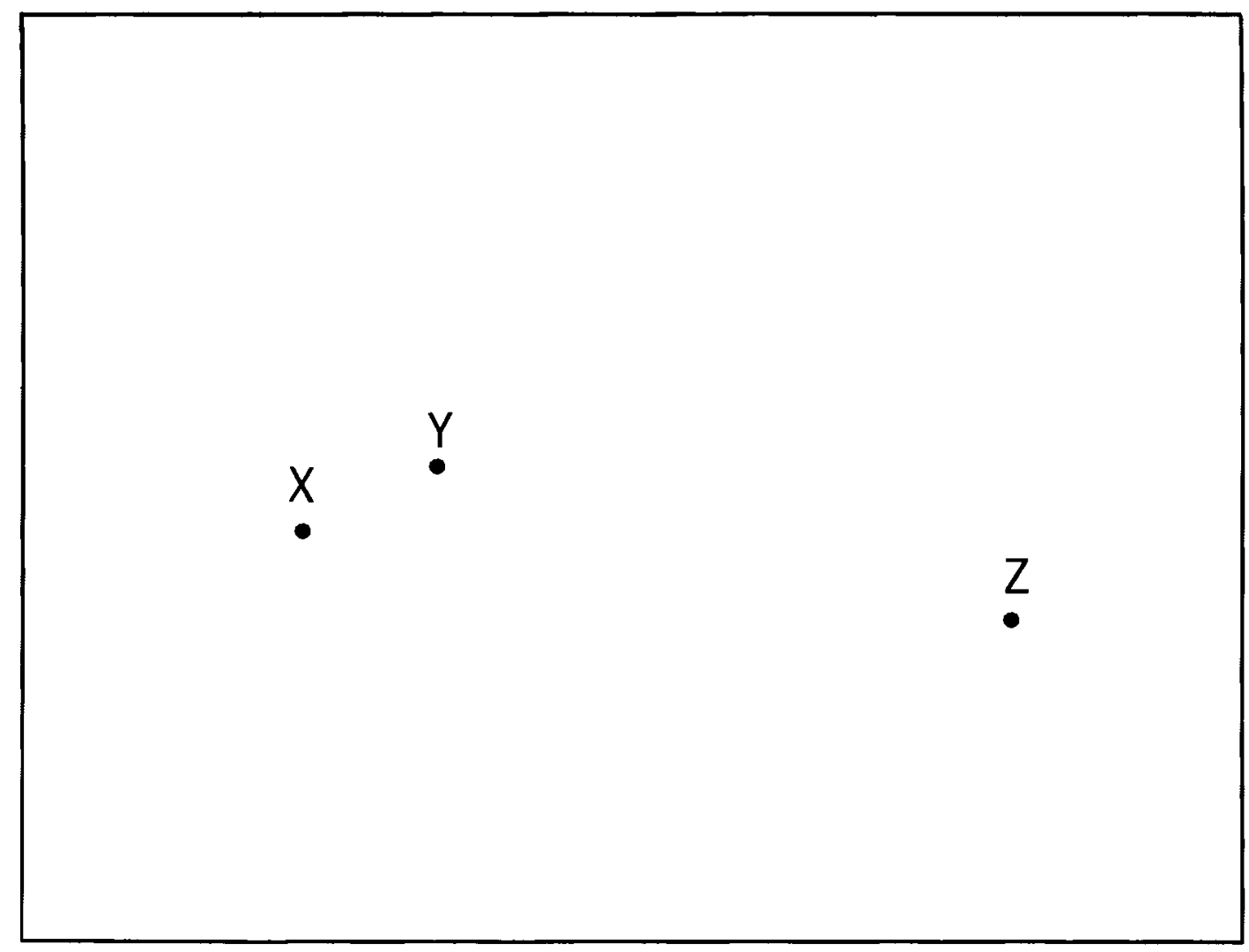

FIGURE 1

Example of Observations of a Spatial Phenomenon 
extreme fluctuations in contours when there are few data points. Kriged contours tend to be more stable over distance if the data are sparse. In addition, kriging produces an associated measure of uncertainty (kriging error) for the contoured surface. This feature can be of real importance for site characterization because part of the work will be the evaluation of the quality of the information obtained, such as the estimated basalt surface.

\section{B. Scope of Study}

The purpose of this study is to evaluate kriging as a tool for characterizing potential repository sites. The characterization of a site is a many-faceted process: from measuring the size of the geologic structure, searching for discontinuities or faults, to evaluating its chemical composition. One aspect of characterization is to have as accurate a map of the location and dimensions of the geologic structure as possible. Kriging's contribution to site characterization is spatial estimation or a surface-mapping capability. It was decided to evaluate its performance for estimating a geologic or hydrogeologic surface, such as water elevation and top of bedrock.

The work was broken down into two tasks. 1) Gain experience with kriging techniques on a "well behaved" phenomenon; that is, one that can be adequately described by a continuous function. 2) Evaluate kriging on a data set more characteristic of the data used to evaluate a site: less well behaved phenomenon and fewer data points. An example of this type of data would be top of a geologic structure or its thickness from sparse core data. The Hanford Wells Data Base (containing water potential and other geologic information) proved to be useful for two reasons: it was readily accessible, and because of its 300-plus wells, provided a rather 
complete data set for the purpose of this study. Water elevation was chosen to be the data set for the first task. The basalt elevations were chosen for the second task because they are a less complete data set (half the size of the water elevation data set); also a typical basalt surface is of interest since basalt under or near the Hanford Reservation is a candidate for a waste repository. The top-of-basalt surface is also known to be a much rougher surface and therefore much harder to model. The objective of the study was then to contour basalt and water elevations using kriging techniques.

II. KRIGING

A. Overview of Kriging Theory

Kriging is a statistical spatial estimation technique. In contrast to deterministic models it makes no attempt to describe the physical mechanism of the underlying phenomenon; instead it models, using statistical principles, the structure of the available spatially-distributed data to provide as accurate an estimate as possible of the contours of a geologic phenomenon.

The basic idea of kriging grew out of a problem encountered in the South African gold fields: that of estimating the ore grade in a mining unit from blast or bore hole data. A straight average of the bore hole ore grades often led to erroneous predictions; and, in addition, it was felt there should be a systematic method to use information contained in adjacent mining units.

Named after D. G. Krige, the South African mining engineer who first described the problem, the techniques were generalized, given mathematical rigor, and named the theory of regionalized variables by $G$. Matheron of the Paris School of Mines.

Although kriging is heavily oriented to mining problems because of its origins, the techniques are general and can be applied to any spatial phenomenon, such as the contouring of groundwater potential and air 
pollution concentrations, the mapping of a geologic surface, or the delineation of an oil field.

The trend surface approach to spatial estimation is based on a relationship of the form:

$$
Z(\underline{x})=F(\underline{x})+\varepsilon(\underline{x}) \text {. }
$$

The term $Z(\underline{x})$ is the observed value of the phenomenon at location $\underline{x} ; F(\underline{x})$ is a function that describes a systematic or predictable component and $\varepsilon(\underline{x})$, called noise, or error, is a random component. The trend surface method assumes that for various locations $\underline{x}$, the terms $Z(\underline{x})$ are not related because the object of the analysis is to find a function $F(\underline{x})$ that reduces the terms $\varepsilon(\underline{x})$ to white noise. However, in practice, the errors often appear correlated. Kriging is also based on a linear relationship:

$$
Z(\underline{x})=m(\underline{x})+u(\underline{x})
$$

however, the terms $m(\underline{x})$ and $u(\underline{x})$ are interpreted differently than in trend surface analysis. The term $m(\underline{x})$, called the drift, is a function that describes a deterministic component. However, in contrast to trend surface methods, kriging places importance in the term $u(\underline{x})$, which is not assumed to be totally random, but to have a structure. This means that for two locations say $\underline{x}_{1}$ and $\underline{x}_{2}, u\left(\underline{x}_{1}\right)$ and $u\left(\underline{x}_{2}\right)$ are related and the relationship can be described as a function of the intervening distance. Kriging utilizes this structure to provide the "best" estimate of $Z(\underline{x})$ at location $\underline{x}$ from the surrounding data.

Like trend surface analysis, kriging is a linear estimation technique, but it calculates the estimates differently from the standard regression method of trend surface analysis. Suppose we have $N$ locations $\underline{x}_{7}, \ldots, \underline{x}_{N}$ 
for which we have observations $Z\left(\underline{x}_{1}\right), \ldots, Z\left(\underline{x}_{N}\right)$. We then want to estimate the value of $Z$ at some new location $\underline{x}_{0}$; we do this by a linear combination of the $Z\left(\underline{x}_{j}\right)^{\prime} s$. The kriging estimate, denoted $Z^{\star}\left(\underline{x}_{0}\right)$, is

$$
Z^{*}\left(\underline{x}_{0}\right)=\sum_{i=1}^{N} \lambda_{i} Z\left(\underline{x}_{i}\right)
$$

where the coefficients $\lambda_{j}$ are called the kriging weights. How these weights are calculated differentiates kriging from trend surface techniques.

Recall that we have assumed that we can represent a spatial phenomena as

$$
Z(\underline{x})=m(\underline{x})+u(\underline{x})
$$

but every term is unique; i.e., it is a function of the location $x$. In order to use statistical theory to estimate $Z\left(\underline{x}_{0}\right)$, we need replication. To obtain a type of replication, we have to make some assumption. Matheron assumes that the first order difference (or increment),

$$
Z(\underline{x}+\underline{h})-Z(\underline{x})
$$

forms a stationary process, which he calls the Intrinsic Hypothesis. This means that for two locations, say $\underline{x}_{1}$ and $\underline{x}_{2},\left[Z\left(\underline{x}_{1}+\underline{h}\right)-Z\left(\underline{x}_{1}\right)\right]$ and $\left[Z\left(\underline{x}_{2}+\underline{h}\right)-Z\left(\underline{x}_{2}\right)\right]$ have the same probability distribution. The only thing that affects the distribution is $\underline{h}$. This may not be totally realistic in practice, but it is a better (less restrictive) assumption than assuming that $Z(\underline{x})$ itself must be stationary. Kriging does not require that the Intrinsic Hypothesis hold throughout the entire field of interest, but only over the distance used to make an estimate. This property is called local stationarity, which wil1 be discussed in more detail later. 
The heart of the kriging approach to spatial estimation has three equally important aspects:

1) maximum range over which data are taken to make an estimate,

2) drift, and

3) variogram structure.

The three are mutually dependent so in practice must be considered simultaneously; one cannot specify them sequentially. A description of each and a discussion of how they interact will explain the kriging estimation procedure.

Range

Since kriging is a local estimation procedure, the surrounding data are used to estimate the value at a specified point. However, the question of how many data points to use and over what distance they should be taken is a complex one. It certainly depends on the proximity of the data to the point of interest. Generally, the more data used to make an estimate the better. However, for spatial estimation there are cases where this is not true. If one is trying to estimate a geologic unit elevation in the bottom of a valley, the elevation of that unit at a nearby mountain is worse than no help; it can lead to erroneous results. This is an example of drift which we will discuss next.

Drift

For kriging, the drift is the systematic component $m(\underline{x})$ of Equation 1 . Drift tends to be a large scale phenomenon. If the distance over which data are drawn to make an estimate is smaller than the distance over which the drift begins to exert its influence, then the Intrinsic Hypothesis holds. However, there is a conflicting objective: to use all of the information in 
the surrounding data to estimate $Z\left(\underline{x}_{0}\right)$. How does one decide when a data point contains relevant information? This is provided by the variogram which witl be discussed next.

Variogram

The variogram provides information on the form of the relationship between two observations, say water elevations, as a function of the intervening distance.

The variogram is defined as

$$
\gamma(|\underline{h}|)=(1 / 2) E(Z(\underline{x}+\underline{h})-Z(\underline{x}))^{2}
$$

where the $E(\cdot)$ notation represents mathematical expectation (that is, moments of a function). It is estimated empirically by

$$
\frac{1}{2 N} \sum_{\underline{x}}(Z(\underline{x}+\underline{h})-Z(\underline{x}))^{2},
$$

the average squared difference between two data points $\underline{h}$ distance apart. Under the assumption of no drift, that is

$$
\begin{aligned}
& E(Z(\underline{x}))=m, \text { a constant, } \\
& E(Z(\underline{x}+\underline{h})-Z(\underline{x}))^{2}=\operatorname{Var}(Z(\underline{x}+\underline{h})-Z(\underline{x}))
\end{aligned}
$$

Which is tie variarice of the first order increment (2). Assume that

$$
E(Z(\underline{x}))=m(\underline{x}) \text {, }
$$

then $E(Z(\underline{x}+\underline{h})-Z(\underline{x}))^{2}=\operatorname{Var}(Z(\underline{x}+\underline{h})-Z(\underline{x}))+(m(\underline{x}+\underline{h})-m(\underline{x}))^{2}$ which overestimates the variance of $(Z(\underline{x}+\underline{h})-Z(\underline{x}))$. The theoretical variogram has several general properties: it is nonnegative; at $|\mathrm{h}|=2, \gamma(|\underline{h}|)=0$; and it is monotonically increasing as the distance increases. There are 
several ways it can behave within the above constraints. The common variograms shown in Figure 2 illustrate the type of information to be obtained from the variogram. Figure 2(a) shows a linear variogram given by the equation

$$
\gamma(|\underline{h}|)=a|\underline{h}|,
$$

where $|\underline{h}|$ is the measure of distance between two points in space. For one dimension, $|\underline{h}|$ is simply the difference between two numbers. For higher dimensions, say two, where a point is represented as a vector $(x, y)$

$$
|\underline{h}|=\sqrt{\left(x_{1}-x_{2}\right)^{2}+\left(y_{1}-y_{2}\right)^{2}} \text {. }
$$

The interpretation of the linear variogram is that the variability between two observations increases linearly (from zero) as the distance between them increases. In theory this continues forever, but in reality there is a limiting distance where one observation provides no information on the value of an observation at a larger distance. This situation is reflected in the next two variograms so they will be discussed together. Figure 2(b) shows a spherical variogram, which is given by

$$
\begin{array}{rlrl}
\gamma(|\underline{\mathrm{h}}|) & =c\left[\frac{3}{2} \frac{|\underline{\mathrm{h}}|}{\mathrm{a}}-\frac{|\underline{\mathrm{h}}|^{3}}{2 \mathrm{a}^{3}}\right]|\underline{\mathrm{h}}| \leq \mathrm{a} \\
& =c & |\underline{\mathrm{h}}|>\mathrm{a}
\end{array}
$$

Figure $2(\mathrm{c})$ presents an exponential variogram which is described by the equation

$$
\gamma(|\underline{h}|)=c\left[1-e^{-\frac{|\underline{h}|}{a}}\right] .
$$




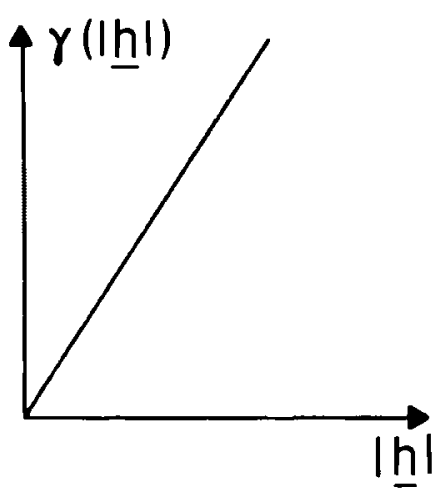

(a)

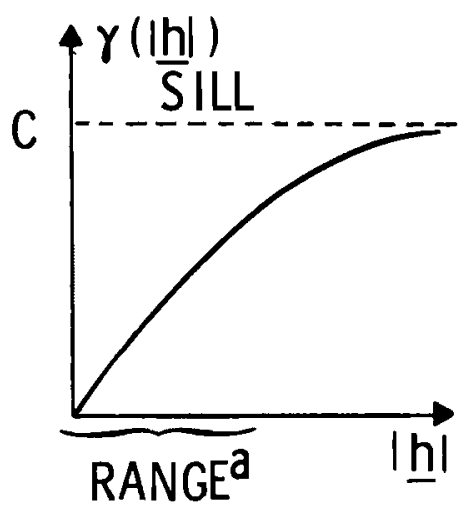

(c)

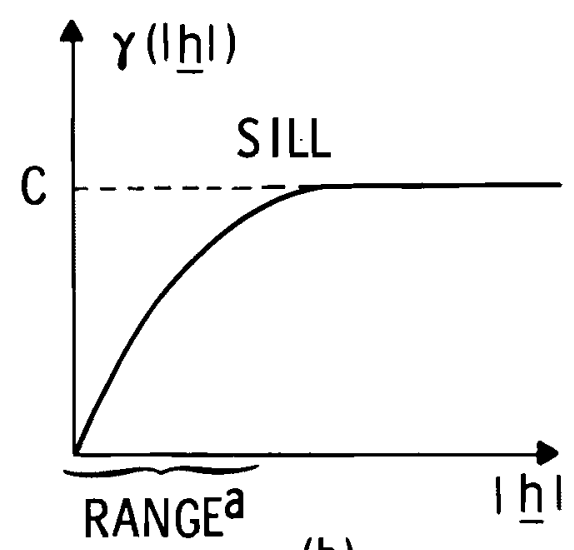

(b)

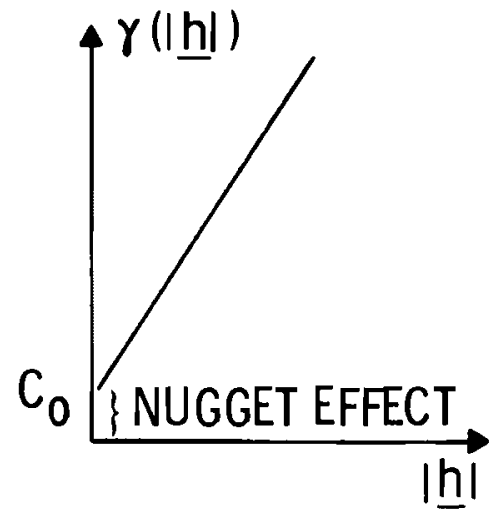

(d)

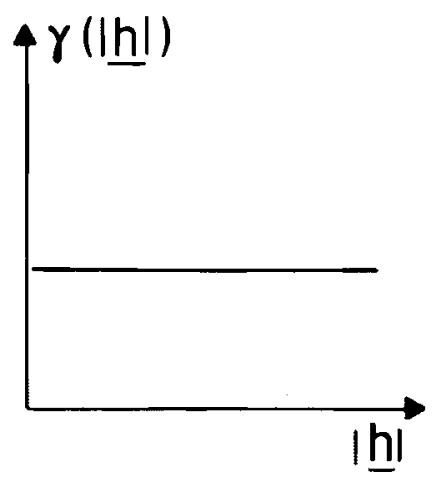

(e)

FIGURE 2

Types of Theoretical Variograms 
The parameters $c$ and a are respectively called the sill and the range. The range is the distance at which the variogram levels off. Observations greater than a distance a apart are no longer related. The sill is the value of the variogram at $|\underline{h}|=C$, or a measure of the basic variability between two unrelated observations. This is the maximum variability in the system. The variogram in Figure $2(d)$ has a discontinuity at $|\underline{h}|=0$. The magnitude of the discontinuity $C_{0}$, is called the nugget effect. The name arose from the gold mining industry where the gold tends to occur in isolated pockets within the substrate. The estimated ore grades from adjacent bore holes could.differ substantially if one of them contained the "pocket" and the other did not. In practice, the nugget effect can result from a combination of other factors besides the discontinuity in the physical phenomena: measurement error in the data, and the size of the sample on which the observation is made. For example a bore hole (the smallest measuring unit), does not have zero mass, so there can be variability within the sample itself. A nugget effect can be added to any of the other variograms to reflect this. The last variogram (Figure 2(e)) is all nugget effect or constant variance. This corresponds to the case of independent observations and $m(\underline{x})$ a constant, which is assumed by the trend surface approach to spatial estimation.

These three factors exert their influence on the estimate of $Z\left(\underline{x}_{0}\right)$ through the kriging equations. Recall that our estimate $Z^{\star}\left(\underline{x}_{0}\right)$ is defined as

$$
Z^{*}\left(\underline{x}_{0}\right)=\sum_{i=1}^{N} \lambda_{i} Z\left(\underline{x}_{i}\right) .
$$

We want our estimator $Z^{*}\left(\underline{x}_{0}\right)$ to have certain optimal statistical properties. For expository reasons, we omit the mathematical details here. For a more 
complete derivation, see the appendix. The first property is unbiasedness which is defined as

$$
E\left(Z *\left(\underline{x}_{0}\right)\right)=E\left(Z\left(\underline{x}_{0}\right)\right) .
$$

Under the assumption of a constant drift this implies that

$$
\sum_{i} \lambda_{i}=1
$$

If the drift is not constant, assume that it can be represented as a sum of monomial terms $f^{\ell}, \ell=0, \ldots, L$ where, for two dimensions,

$$
\begin{aligned}
& f^{0}(\underline{x})=1 \\
& f^{1}(\underline{x})=x \\
& f^{2}(\underline{x})=y \\
& f^{3}(\underline{x})=x y \\
& f^{4}(\underline{x})=x^{2} \\
& f^{5}(\underline{x})=y^{2}, \text { etc. }
\end{aligned}
$$

Then the unbiased condition implies that for each $\ell, \ell=0, \ldots, L$

$$
\sum_{i=1}^{N} \lambda_{i} f^{l}\left(\underline{x}_{i}\right)=f^{l}\left(\underline{x}_{0}\right)
$$

The second optimal property of the kriging estimator is minimum variance. To achieve this, we minimize

$$
\sigma^{2}\left(\underline{x}_{0}\right)=\operatorname{Var}\left(Z^{\star}\left(\underline{x}_{0}\right)-Z\left(\underline{x}_{0}\right)\right)
$$

under the constraint of unbiasedness using the Lagrangian multiplier technique. 
The function to be minimized is

$$
\begin{gathered}
2 \sum_{i=1}^{N} \lambda_{i} \gamma\left(\left|\underline{x}_{i}-\underline{x}_{0}\right|\right)-\sum_{i=1}^{N} \sum_{j=1}^{N} \lambda_{i} \lambda_{j} \gamma\left(\left|\underline{x}_{i}-\underline{x}_{j}\right|\right) \\
-2 \sum_{\ell=1}^{L} \mu_{\ell}\left(\sum_{i=1}^{N} \lambda_{i} f^{\ell}\left(\underline{x}_{i}\right)-f^{\ell}\left(\underline{x}_{0}\right)\right),
\end{gathered}
$$

which leads to a system of linear equations, called the Universal Kriging (UK) equations, given here in matrix form:

$$
\underline{A} \cdot \underline{\Lambda}=\underline{\Gamma} .
$$

The system of equations is solved for the vector $\Lambda$, consisting of the weights $\lambda_{i}$ and the Lagrange multipliers $\mu_{\ell}$. The matrices for $L=2$ are

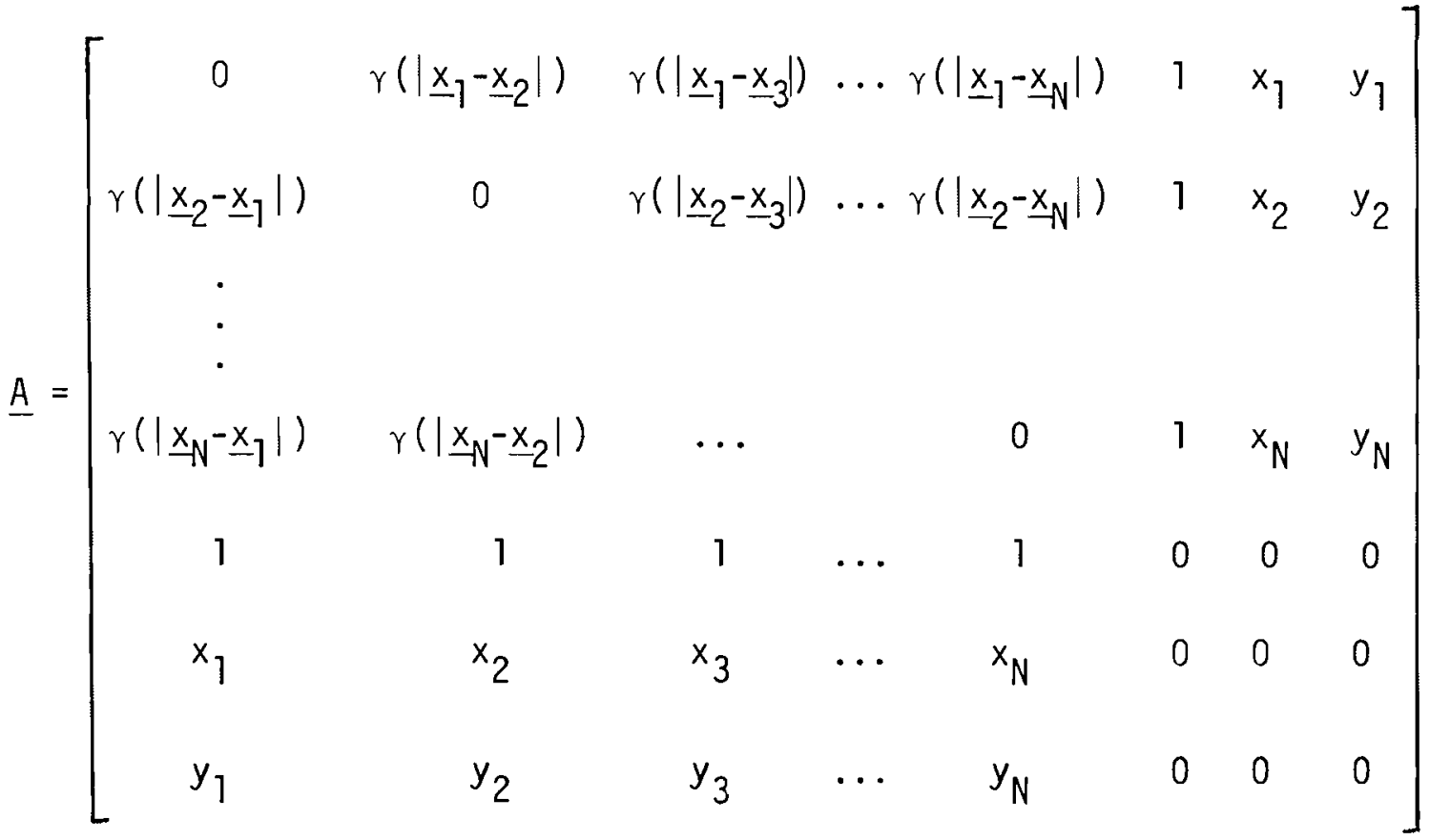

$$
\begin{aligned}
& \Lambda=\left[\begin{array}{c}
\lambda_{1} \\
\lambda_{2} \\
\vdots \\
\lambda_{N} \\
\mu_{0} \\
\mu_{1} \\
\mu_{2}
\end{array}\right] \quad I=\left[\begin{array}{c}
r\left(\left|\underline{x}_{1}-\underline{x}_{0}\right|\right) \\
\gamma\left(\left|\underline{x}_{2}-\underline{x}_{0}\right|\right) \\
\vdots \\
\gamma\left(\left|\underline{x}_{N}-\underline{x}_{0}\right|\right) \\
1 \\
x_{0} \\
y_{0}
\end{array}\right]
\end{aligned}
$$


A detailed derivation is given in the appendix.

At this point it may be helpful to compare the kriging estimation procedure to that of trend surface analysis. In trend surface analysis the difference between the true surface and the estimated surface can be assumed to be a minimum only at data points. Kriging was designed to produce estimates which minimize this difference at locations where there are no data. It can do this because the optimum kriging weights depend only on the location of the data and the form of the variogram.

With the estimates for $\lambda$, we then have an estimate of the kriging variance $\sigma_{K}^{2}$. This variance is a theoretical or model variance and not an empirical measure of lack-of-fit, which is what is usually associated with the residual or mean square error in regression. This variance can be interpreted as how much different realizations of the surface could vary with the same underlying drift and variogram structure. This is not strictly a measurement variance in the sense of replication. That is reflected by the nugget effect. The absence of a nugget effect can be interpreted as indicating a good measurement technique, small withinsample variability, and/or a smooth underlying phenomenon.

This variance provides little information on the adequacy of the structure to explain the data. One method to assess the fit of the model to the data is by visual inspection of the contours. An empirical estimate of the kriging variance can be obtained at each data point by deleting the point and estimating it from its neighbors. The estimate of the kriging variance is then

$$
\hat{\sigma}_{K}^{2}=\left(Z^{*}(\underline{x})-Z(\underline{x})\right)^{2}
$$

The point has to be deleted, since the kriged estimate of a data point 
is the observed value. That can be seen from an examination of the kriging equations. These differences can be inspected to look for regions where the model does not fit we11, and using the Intrinsic Hypothesis, statistical tests can be used to evaluate the overall fit of the model to the data.

The drawback to this approach is determining the drift and extracting it from the variogram. Using nonlinear regression techniques to estimate the variogram seems to have been abandoned because it often produces a function which is not a permissible variogram. There is one saving grace, only the order of the drift (constant, linear, quadratic) has to be known; the parameters of the drift cancel out of the kriging equations so there is no need to estimate them.

Another approach to the drift and structure identification problem is to make use of an algebraic property that higher order differencing of variables filters out polynomials in the expectation. Suppose for ease of exposition that we have a one-dimensional phenomenon $Z(x)$ which has a linear drift, that is,

$$
E(Z(x))=a_{0}+a_{1} x .
$$

Then the difference of the two first order differences, such that $x_{2}-x_{1}=x_{1}-x_{0}$,

$$
\left[z\left(x_{2}\right)-z\left(x_{1}\right)\right]-\left[z\left(x_{1}\right)-Z\left(x_{0}\right)\right],
$$

has a zero expectation; that is,

$$
\begin{gathered}
E\left[\left(z\left(x_{2}\right)-z\left(x_{1}\right)\right)-\left(z\left(x_{1}\right)-Z\left(x_{0}\right)\right)\right]=a_{0}+a_{1} x_{2}-a_{0}-a_{1} x_{1} \\
-a_{0}-a_{1} x_{1}+a_{0}+a_{1} x_{0}=a_{1}\left[\left(x_{2}-x_{1}\right)-\left(x_{1}-x_{0}\right)\right]=0 .
\end{gathered}
$$

The phenomenon represented by the second order difference

$$
z\left(x_{2}\right)-2 z\left(x_{1}\right)+z\left(x_{0}\right)
$$


now has zero mean. For two dimensions, a first order difference for the configuration of points

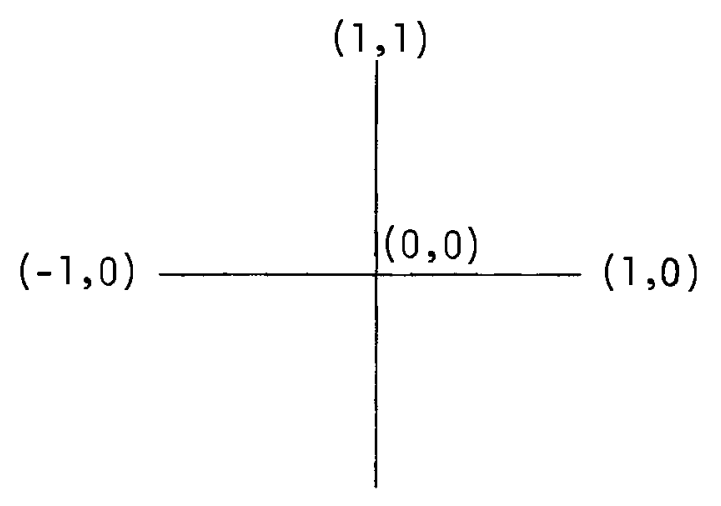

$(0,-1)$

is

$$
Z(1,0)+Z(-1,0)+Z(1,1)+Z(0,-1)-4 Z(0,0)
$$

If we let the coefficients of the $Z\left(\underline{x}_{j}\right)$ 's be denoted $\lambda_{i}$, then

$$
\sum_{i=1}^{N} \lambda_{i} f_{i}^{\ell}=0,0 \leq \ell \leq L
$$

where $L$ is respectively, 1 and 0 , for these two examples. Sums with this property are called generalized increments. In general, a $(k+1)$ st order difference with the above property is a kth order increment. A second order increment (the difference between two first order increments) in one dimension is given by

$$
\left[Z\left(x_{3}\right)-2 Z\left(x_{2}\right)+Z\left(x_{1}\right)\right]-\left[Z\left(x_{2}\right)-2 Z\left(x_{1}\right)+Z\left(x_{0}\right)\right]
$$

it filters out quadratic, linear and constant terms with $L=2$. The original random function $Z(\underline{x})$ is called an intrinsic random function of order $k$ (abbreviated k-IRF) where $k$ is the highest degree polynomial filtered. 
The purpose of taking generalized increments is to produce a stationary regionalized variable from one with a drift. This is the n-dimensional analog of the Box-Jenkins approach to time series analysis. The advantage to this is that the covariance structure of the spatial variable can be estimated without the effects of the drift. This is done by studying the generalized covariance of the k-IRF which differs from the variogram, which is only legitimate for the 0-IRF case.

Let $Z(\lambda)$ be a generalized increment,

$$
\sum_{i} \lambda_{i} Z\left(\underline{x}_{i}\right),
$$

of a $k-\operatorname{IRF} Z(\underline{x})$. Then the variance of the generalized increment is given by

$$
E\left[(Z(\lambda))^{2}\right]=\sum_{i} \sum_{j} \lambda_{i} \lambda_{j} K\left(\left|\underline{x}_{i}-\underline{x}_{j}\right|\right),
$$

where the function $k(|h|)$ is called the generalized covariance function. There are various classes of functions that satisfy the conditions of a covariance, but one class with nice properties for identification purposes (that is, linear in the coefficients) is the class of polynomial generalized covariances. The form of these generalized covariances, which depends on the order of the increment, is listed in Table 1.

\begin{tabular}{|c|c|c|}
\hline Drift & $\mathrm{k}$ & Polynomial Generalized Covariance Model \\
\hline Constant & 0 & $k(|\underline{h}|)=c \delta-b_{0}|\underline{h}|$ \\
\hline Linear & 1 & $K(|\underline{h}|)=c \delta-b_{0}|\underline{h}|+b_{1}|\underline{h}|^{3}$ \\
\hline Quadratic & 2 & $K(|\underline{h}|)=c \delta-b_{0}|\underline{h}|+b_{1}|\underline{h}|^{3}-b_{2}|\underline{h}|^{5}$ \\
\hline
\end{tabular}

\section{TABLE 1}


The conditions imposed on the coefficients are as follows:

in $\mathrm{R}^{2}$ (two-dimensional space):

$$
c \geq 0, b_{0} \geq 0, b_{2} \geq 0, b_{1} \geq-(10 / 3) \sqrt{b_{0} b_{1}}
$$

in $\mathrm{R}^{3}$ (three-dimensional space):

$$
c \geq 0, b_{0} \geq 0, b_{2} \geq 0, b_{1} \geq-\sqrt{10} \sqrt{b_{0} b_{1}}
$$

Note that for $k=0$, the only covariance function is a linear one which is much more restrictive than the variograms given in Figure 2 . How does the generalized covariance compare to the variogram in the D-IRF case? Let $Z(\lambda)=Z\left(\underline{x}_{j}\right)-Z\left(\underline{x}_{j}\right)$; then it can be shown that

$$
\left.K\left(\left|\underline{x}_{i}-\underline{x}_{j}\right|\right)=-\underline{\gamma}^{\prime}\left|\underline{x}_{i}-\underline{x}_{j}\right|\right)
$$

We have shown that for a non-stationary process, we can produce a stationary one by forming the $k^{\text {th }}$ order increments. We can then estimate, from the generalized covariance, the covariance structure of the stationary process. The question is, how does this help us to estimate the nonstationary process? Recall that, from the unbiasedness condition introduced earlier, the sum of the kriging coefficients for the estimate,

$$
Z^{\star}\left(\underline{x}_{0}\right)=\sum_{i} \lambda_{i} Z\left(\underline{x}_{i}\right)
$$

of $Z\left(\underline{x}_{0}\right)$ satisfy

$$
\sum_{i=1}^{N} \lambda_{i}=1 .
$$


Consider the kriging error $\left(Z^{\star}\left(\underline{x}_{0}\right)-Z\left(\underline{x}_{0}\right)\right)$ and define the coefficient of $Z\left(\underline{x}_{0}\right)$ to be

$$
\lambda_{N+1}=-1,
$$

then for $Z^{\star}\left(\underline{x}_{0}\right)-Z\left(\underline{x}_{0}\right)$,

$$
\sum_{i=1}^{N+1} \lambda_{i}=0
$$

Therefore, the kriging error is a generalized increment.

The mechanics of the estimation process are similar to the UK situation. Recall that if $\left(Z *\left(\underline{x}_{0}\right)-z\left(\underline{x}_{0}\right)\right)$ is a generalized increment of order $k$,

$$
E\left(Z^{*}\left(\underline{x}_{0}\right)-Z\left(\underline{x}_{0}\right)\right)=0 .
$$

Since we assume a polynomial drift, this implies that

$$
\sum_{i} \lambda_{i} f^{\ell}\left(\underline{x}_{i}\right)=f^{\ell}\left(\underline{x}_{0}\right) \text { for } 0 \leq \ell \leq L(k)
$$

where $L(k)$ is the value of $L$ associated with a kth order increment; these are the familiar unbiasedness conditions of the UK. The variance of the generalized increment is

$$
\begin{aligned}
& E(Z(\lambda))^{2}=E\left(Z *\left(\underline{x}_{0}\right)-Z\left(\underline{x}_{0}\right)\right)^{2} \\
& =\sum_{i} \sum_{j} \lambda_{i} \lambda_{j} K\left(\left|\underline{x}_{i}-\underline{x}_{j}\right|\right) \\
& =K\left(\left|\underline{x}_{0}-\underline{x}_{0}\right|\right)-2 \sum_{i} \lambda_{i} K\left(\left|\underline{x}_{i}-\underline{x}_{0}\right|\right)+\sum_{i} \sum_{j} \lambda_{i} \lambda_{j} K\left(\left|\underline{x}_{i}-\underline{x}_{j}\right|\right) .
\end{aligned}
$$


As for the UK case, minimizing the variance of the generalized increment under the unbiasedness constraints leads to the system of equations:

$$
\begin{aligned}
& \sum_{j=1}^{N} \lambda_{j} K\left(\left|\underline{x}_{i}-\underline{x}_{j}\right|\right)=K\left(\left|\underline{x}_{i}-\underline{x}_{0}\right|\right)+\sum_{\ell=0}^{L(k)} \mu_{\ell} f^{\ell}\left(\underline{x}_{j}\right) \quad i=1, \ldots, N \\
& \sum_{i} \lambda_{i} f^{\ell}\left(\underline{x}_{j}\right)=f^{\ell}\left(x_{0}\right) \quad l=0, \ldots, L(k) .
\end{aligned}
$$

This system is the same as for the UK except that $K(|\underline{h}|)$ is used in place of $r(\underline{|h|} \mid)$.

This section was designed to give a brief introduction to the kriging theory. It was purposely kept as non-mathematical as possible. For a more complete treatment of the theory consult the papers in the reference section. We next turn to a description of the computer codes BLUEPACK and GAMMA which perform the computations outlined in this section.

\section{B. Computer Codes}

GAMMA and BLUEPACK are computer codes written primarily by P. Delfiner of the Paris School of Mines, Center for Geostatistics. They are flexible, modular, and user-oriented packages currently available in IBM and CDC versions. The current releases can handle one and two dimensions; a new release to be available during the first half of 1979 will reportedly handle the third dimension.

These codes are currently installed on a CDC 6600 at the Las Vegas Department of Energy computing facility and can be used for any DOE-funded project. They are maintained by Desert Research Institute (DRI) personnel in time-share mode, so that they can be accessed interactively over commercial and Federal Telecommunications System lines. The purchase agreement 
between DOE and the School of Mines stipulates that the codes cannot be implemented at any other installation outside of DRI's Las Vegas and Reno facilities.

GAMMA

GAMMA calculates the empirical variogram,

$$
\hat{\gamma}(|\underline{h}|)=\frac{1}{2 N} \sum_{\underline{x}}[Z(\underline{x})-Z(\underline{x}+\underline{h})]^{2} .
$$

Up to this point there has been no mention of a direction, as well as a distance, effect on a spatial variable; however, this is often the case. An example is ground elevation along a ridge compared to the elevation perpendicular to the ridge. The elevations along the ridge should show more similarity at the same distance than those at right angles to it. These directional effects are called anisotrophies.

GAMMA calculates a total of five variograms: one for each of four directions (north-south, east-west, northwest-southeast, and southwestnortheast), and a variogram which is the average of the four directional variograms. Since the data are usually not equally spaced, in order to calculate a variogram for two-dimensional data, the plane is divided into eight sectors of $45^{\circ}$ about each of the direction lines. The sectors are further partitioned into distance classes by concentric circles whose spacing is specified by the user (Figure 3 ). For example, if the distance between classes is 100 feet, all pairs of points, $Z(\underline{x})$ and $Z(\underline{x}+\underline{h})$, for which $\underline{h}$ lies in the NE or SW sectors and $|\underline{h}|<100$ will contribute to the estimation of the point of the NE-SW variogram at distance $|\overline{\underline{h}}|$, the average distance in that distance class. 


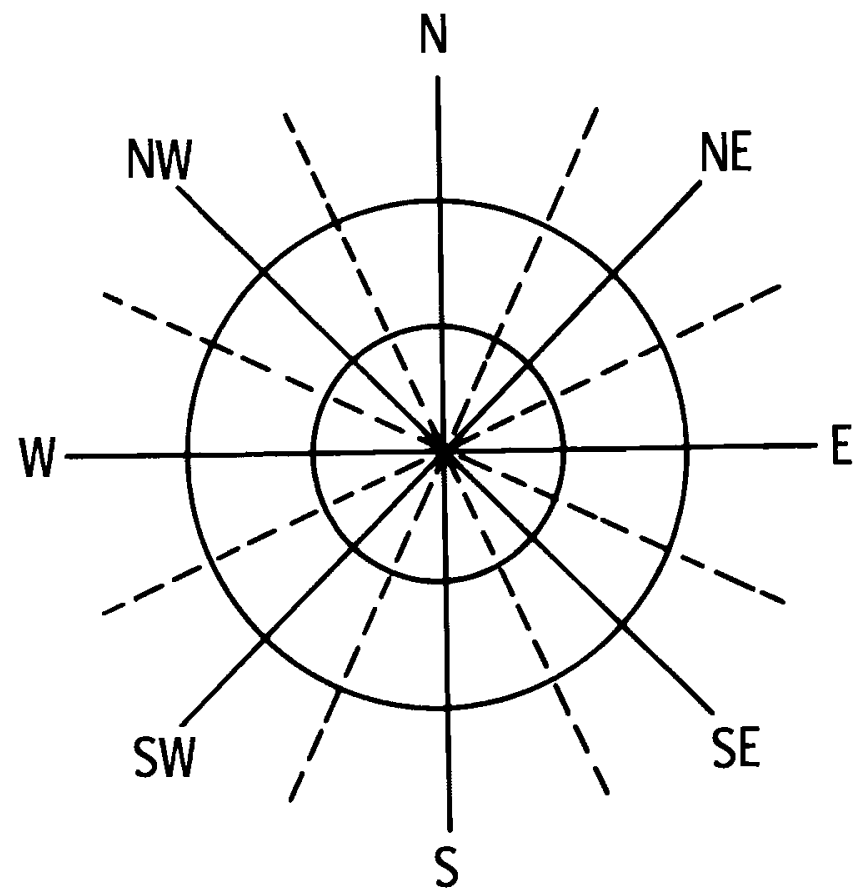

FIGURE 3

Diagram of Direction and Distance Classes Used for Empirical Variogram Computation

The reason for calculating directional variograms is to detect anisotrophies, which can be a serious problem in calculating the kriging estimates. Recall that only one variogram is used in the system of equations (3). If there are anisotrophies, which variogram should be used? Certain types of anisotrophies can be corrected by a translation of the coordinates $\underline{x}$ of the data points (Huijbregts, 1975)).

In practice, many geologic phenomena become anisotrophic as the distance between data points increases; the water and basalt elevation data presented in Section III exhibit this behavior. However, if the anisotrophies occur at larger distances than needed for the local grid estimation, they are of little concern. Anisotrophies and the estimation and use of the variogram will be discussed more fully in the context of the analysis of the data in Section III. 
BLUEPACK

BLUEPACK computes the kriging estimates and standard (kriging) errors. The main feature of BLUEPACK is the estimation of points on a regular grid, which is preliminary to producing contours of a spatial phenomenon. It will do other things as we11: estimation of a surface at isolated points, block or area estimation, estimation of the surface at data points by the leave-one-out method. However, we will be primarily concerned with grid estimation and the estimation at the data points.

There are two approaches to estimation possible in BLUEPACK. The first is by the user specifying the drift and variogram structure. The kriged estimate of the surface and its standard error at each grid node are produced from the solution of the UK equations (3) for the $\lambda$ 's. Taken together the estimates and their standard errors for all the grid nodes constitute the kriged model of the surface. The model is the minimum variance, unbiased estimate of the surface under the assumed drift and variogram structure. However, it does not provide a means to test the adequacy of that assumption with respect to the data; the next method described does this. The other method, called automatic structure identification, implements the $k$-IRF theory described in Section IIA to select a $k^{\text {th }}$ order increment, corresponding to the order of the drift, and a covariance function that best describes the structure of the data. The estimate of the surface and kriging error at each grid node is calculated from the solution of equations (4). An advantage of automatic structure identification is that it avoids biases in estimating the variogram when a drift exists; the data are used directly to select the structure and the selection procedure is based on statistical criteria. The three possible orders of drift that are considered are constant, linear, and quadratic. A selected subset of 
the data is divided into two groups and each data point is predicted from the data in the other group, assuming first a constant, then a linear, and finally a quadratic drift. For each data group, the three drift structures are ranked on the size of their mean squared error,

$$
\frac{1}{N} \sum_{i} z\left(\lambda_{i}\right)^{2}
$$

The order of the drift producing the smallest average rank over all of the data points is considered the "best."

Once the order of the drift has been chosen, the number of functions which are candidates for the generalized covariance is automatically determined. They consist of all possible combinations of terms from the equations in Table 1. For example, for a constant drift, the three possible covariance functions are

$$
\begin{aligned}
& K(|\underline{h}|)=c, \\
& K(|\underline{h}|)=-b_{0}|\underline{h}|, \\
& K(|\underline{h}|)=c-b_{0}|\underline{h}| .
\end{aligned}
$$

The higher the order of the drift, the larger the number of possible covariance functions. All possible covariance functions are then used to estimate the data points in one group using the data in the other group; the functions are then compared on the basis of the ratio

$$
\frac{\sum_{i} z\left(\lambda_{i}\right)^{2}}{\sum_{i} K\left(\left|h_{i}\right|\right)}
$$

The three covariance functions having a jackknife ${ }^{1}$ statistic closest to 1.0 are selected for testing on a representative (with respect to location)

See appendix. 
subset of data points. The covariance function that is finally chosen is the one which minimizes the following two criteria: the mean squared error,

$$
\frac{1}{N} \sum_{\underline{x}}\left(Z^{*}(\underline{x})-Z(\underline{x})\right)^{2},
$$

and the standardized mean squared error,

$$
\frac{1}{N} \sum_{\underline{x}} \frac{\left(Z^{\star}(x)-Z(x)\right)^{2}}{\sigma_{K}^{2}(x)}
$$

If no covariance function minimizes the two criteria, the one with the best jackknife statistic is chosen.

The adequacy of the chosen model with respect to the entire data set can be evaluated using universal kriging to estimate each data point from its neighbors. This is called a verification analysis and its use is illustrated in Section III.

Another feature of BLUEPACK that has proved useful for this work is the FAULT option. It allows the user to screen off an area of the grid from unrelated adjacent areas. The motivation for this option grew out of the need to deal with surface discontinuities such as geologic faults. The use of the FAULT option preserves discontinuities which would otherwise be smoothed.

BLUEPACK produces printer-plots of the contours obtained from the grid estimates; however, they are difficult to read. The contour plots in this report were produced by linear interpolation using Pacific Northwest Laboratories Water and Land Resources Department graphics equipment and software. 


\section{PRACTICAL RESULTS}

\section{A. Description of Data}

The Hanford Site is located within the Pasco Basin, in the northcentral portion of the physiographic province known as the Columbia River Plateau (Figure 4). The main geologic features of the Hanford Site are shown in Figure 5. The Columbia River Plateau contains one of the largest deposits of continental tholeiitic basalts in the world (ARHCO, 1976 and Lillie and Richard, 1977). The basalt under the site is being considered as a potential waste repository (ARHCO, 1976).

Some 2200 wells drilled in various locations within the Site boundaries (Figure 6) are collectively known as the Hanford Wells. They were not all drilled for the same purpose. Approximately 200 are old farm wells and largely abandoned. The newer wells were either drilled by DOE prime contractors or the U.S. Geological Survey. The majority of the 1700 functioning wells are used for groundwater hydrological data collection or basalt stratigraphic characterization. The wells are currently the responsibility of Rockwe 11 Hanford Operations.

About 850 wells are drilled into the groundwater table. From them, periodic measurements of groundwater potential (among others) are taken. There are approximately 190 wells drilled into the basalt bedrock, providing information on the location of the top of basalt. The Water and Land Resources Department of Pacific Northwest Laboratories (PNL) maintains data from the wells in what is called the Hanford Wells Data Base. The well locations are referenced with respect to a rectangular grid system (measured in feet) whose origin is at the southwest boundary of the Hanford Site. The area covered by the grid is approximately 144,000 feet (27 miles) by 172,000 feet (32 miles). For comparison purposes, we have used the same 


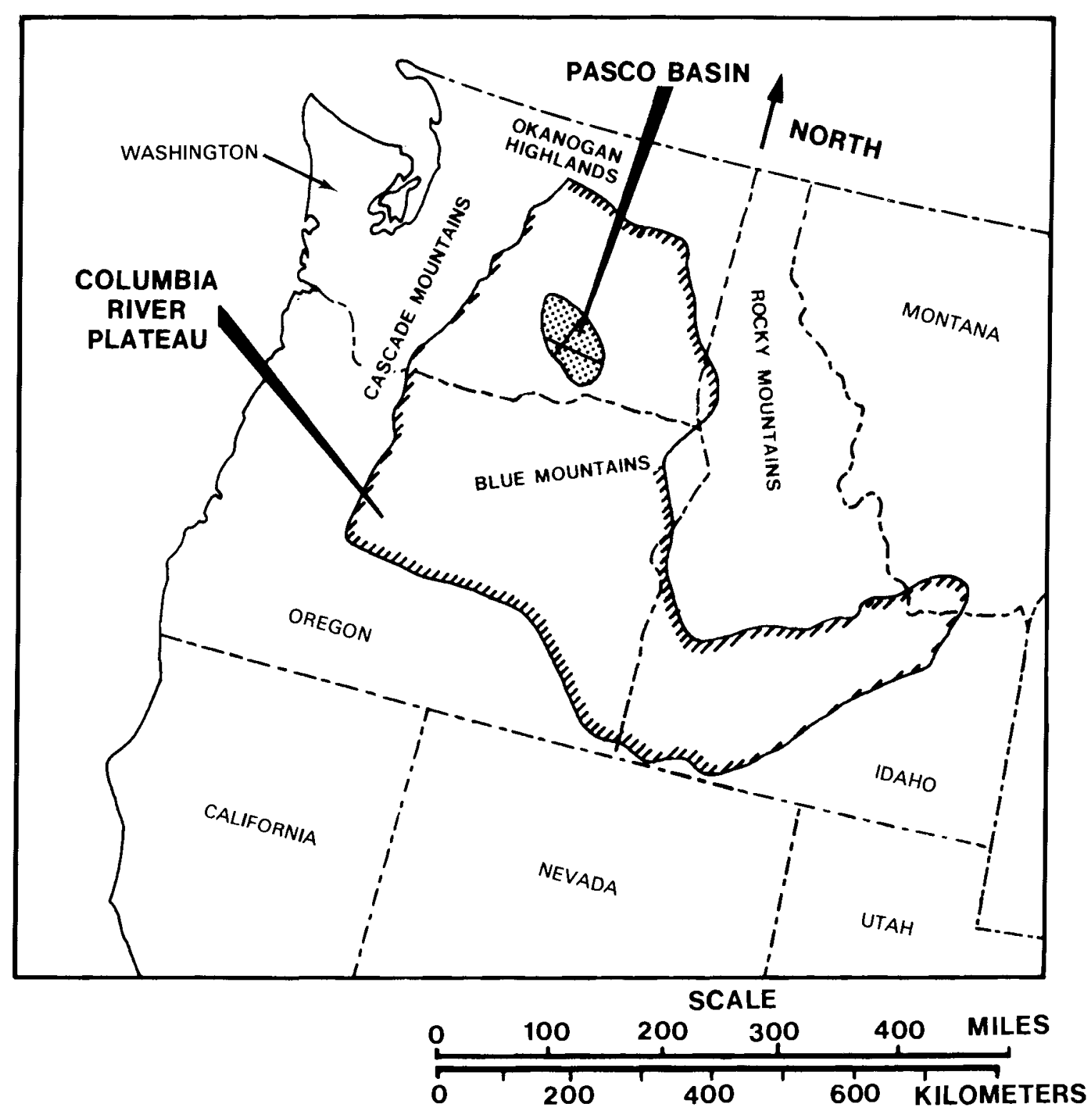

FIGURE 4

Location of the Pasco Basin within the Columbia River Plateau (After LiTlie and Richard, 1977) 


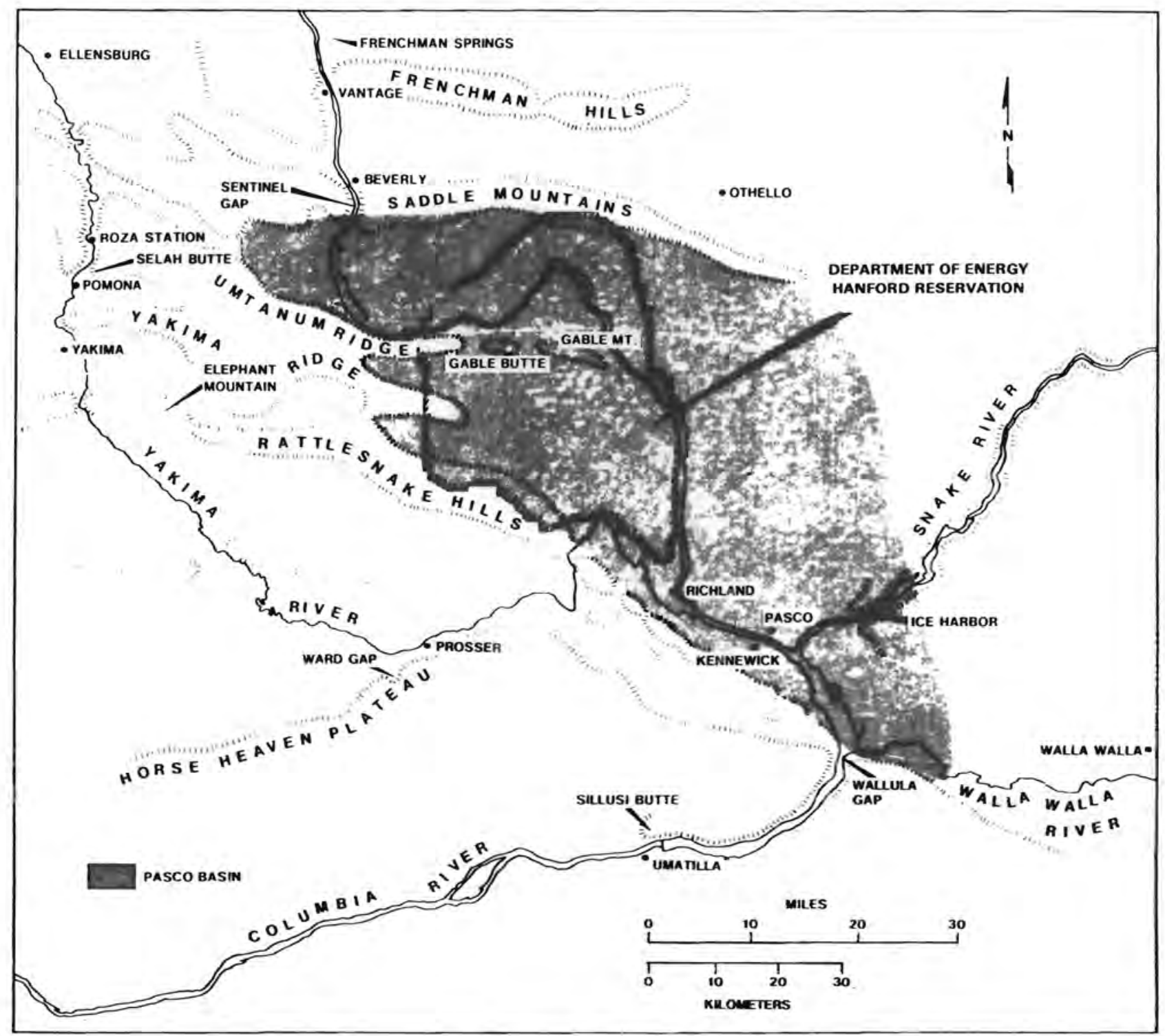

FIGURE 5

Major Features of the Pasco Basin (After Lillie and Richard, 1977) 


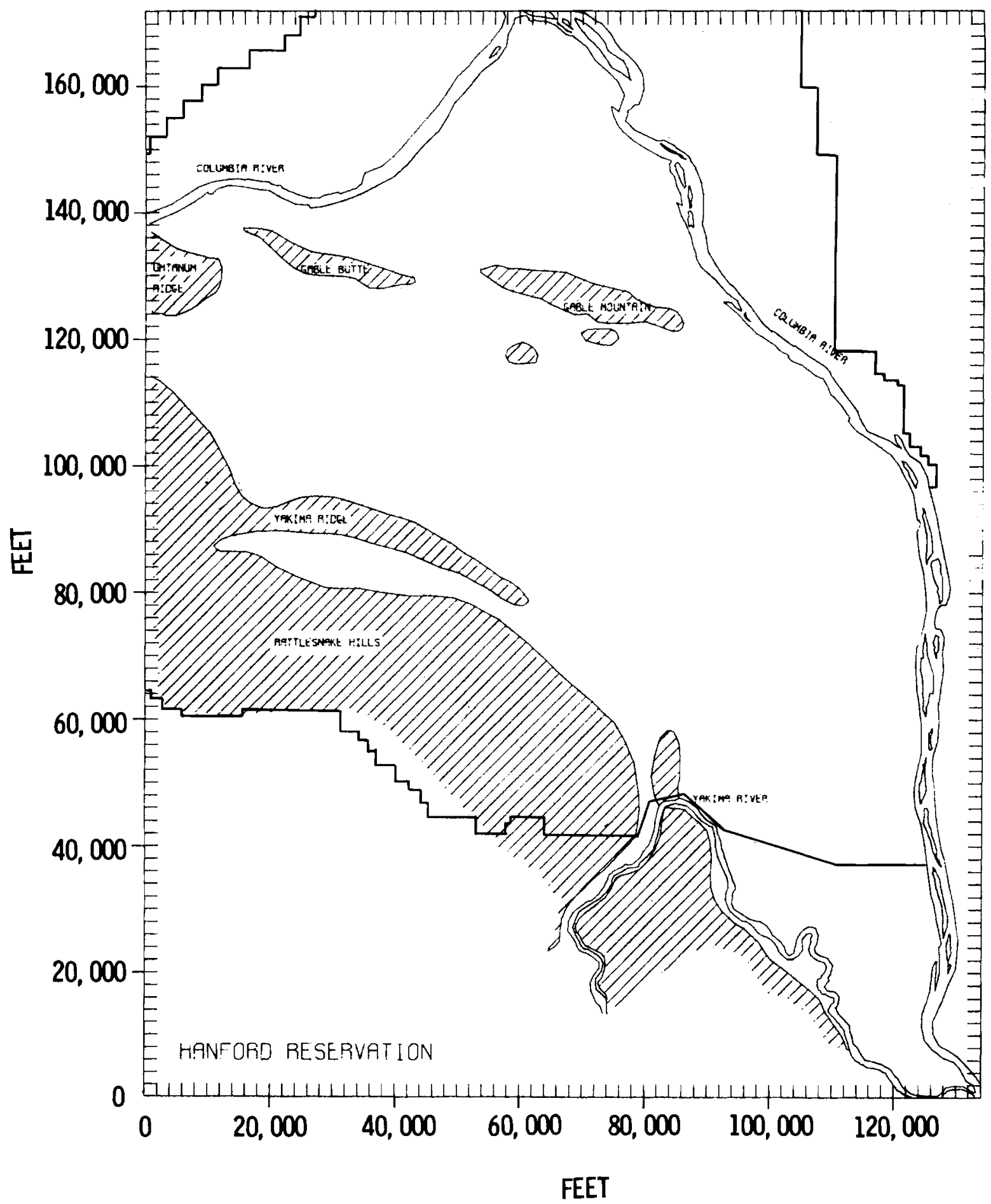

FIGURE 6

Major Above-Ground Geologic Structures of the Hanford Reservation 
grid size (2000 feet by 2000 feet) which is customarily used by PNL to generate the groundwater potential contours for the Site. This grid size was also used for the basalt elevation contours. In this section we first summarize our work with the groundwater data and compare the kriged estimates and standard error contours to the routine potential contour map estimated by conventional methods. We then present the results of our analysis of the basalt data and the kriged estimates and standard error contours of the basalt surface.

\section{B. Hanford Reservation Groundwater Potential}

The two groundwater potential data sets from the Hanford Wells data base were made available to us by PNL's Water and Land Resources Department personne1. They were taken in September 1973 and January 1975, respectively. Groundwater potential is known to be a smooth phenomenon; that is, it tends to change slowly and predictably with distance. For that reason, it should be a fairly easy surface to contour, and hence a good first test for the kriging techniques.

For September 1973, there were water potential data from 332 wells. The locations of the wells are shown in Figure 7 . The data are contained in a rectangle measuring 124,000 feet by 134,000 feet. They are certainly not uniformly distributed throughout the area; because of the activities at the Site they tend to be concentrated in the area between Rattlesnake and Gable Mountains. The water elevations (in feet above sea level) for this period ranged from 340 feet along the Columbia River in the southeast corner of the Site to over 480 feet between Umtanum Ridge and the Rattlesnake Hills.

In order to produce contour estimates for the area covered by the data on a 2000 foot grid, the area had to be divided into four subgrids 


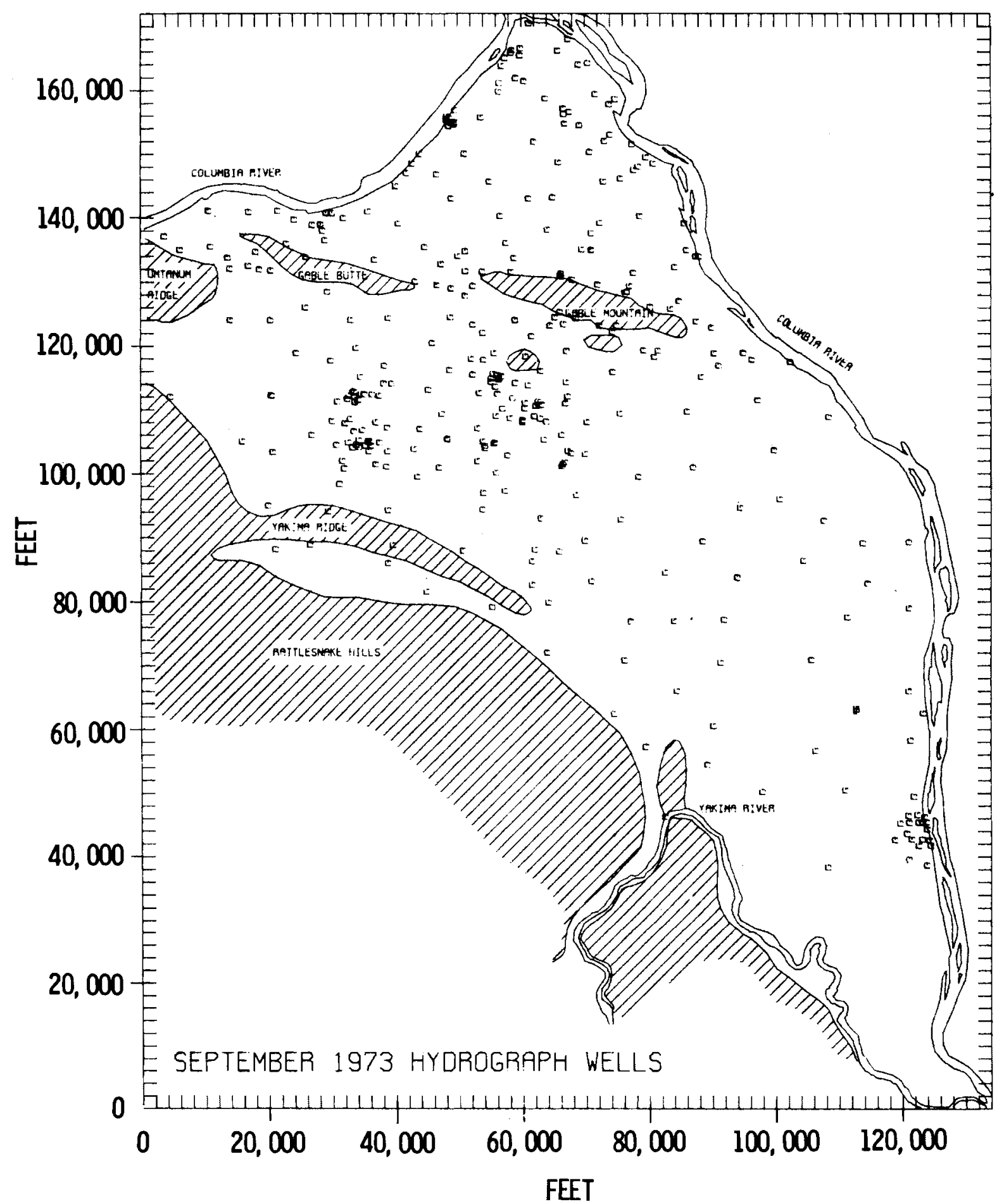

FIGURE 7

Locations of September 1973 Hanford Hydrograph We11s 
in order to not exceed the capacity of BLUEPACK as it is currently implemented at the Department of Energy Las Vegas computing facility. For convenience, the subgrids were of equal size.

The first step in a kriging analysis is to calculate the directional and combined empirical variograms from the data. The average and the two extreme directional variograms for the 1973 water potential data are given in Figure 8; at first sight they have little resemblance to the theoretical variograms discussed in Section II. The theoretical variograms are mathematical constructions, and an idealized version of reality. The empirical variograms represent reality. The fluctuations in the empirical variogram are a result of several things; among them: sampling variability (where the samples were taken), the presence of drift (no phenomenon is ever actually stationary), and measurement variability. In this case, the measurement error is probably negligible since repeat measurements taken at the same location are all within several hundredths of a foot.

The overall impression of the variograms is of no nugget effect and parabolic curve up to about 25,000 feet followed by a leveling off. The absence of a nugget effect suggests a smooth phenomenon, and the parabola, the presence of a drift. The range or sphere of influence appears to be about 25,000 to 30,000 feet.

There are definite anisotropies, but they are probably not too severe up to 10,000 feet. The largest variogram belongs to the east-west direction and the smallest to the northwest-southeast direction. This is reasonable since the major geologic features (mountains and basalt synclines) tend to orient on a northwest-southeast axis. 


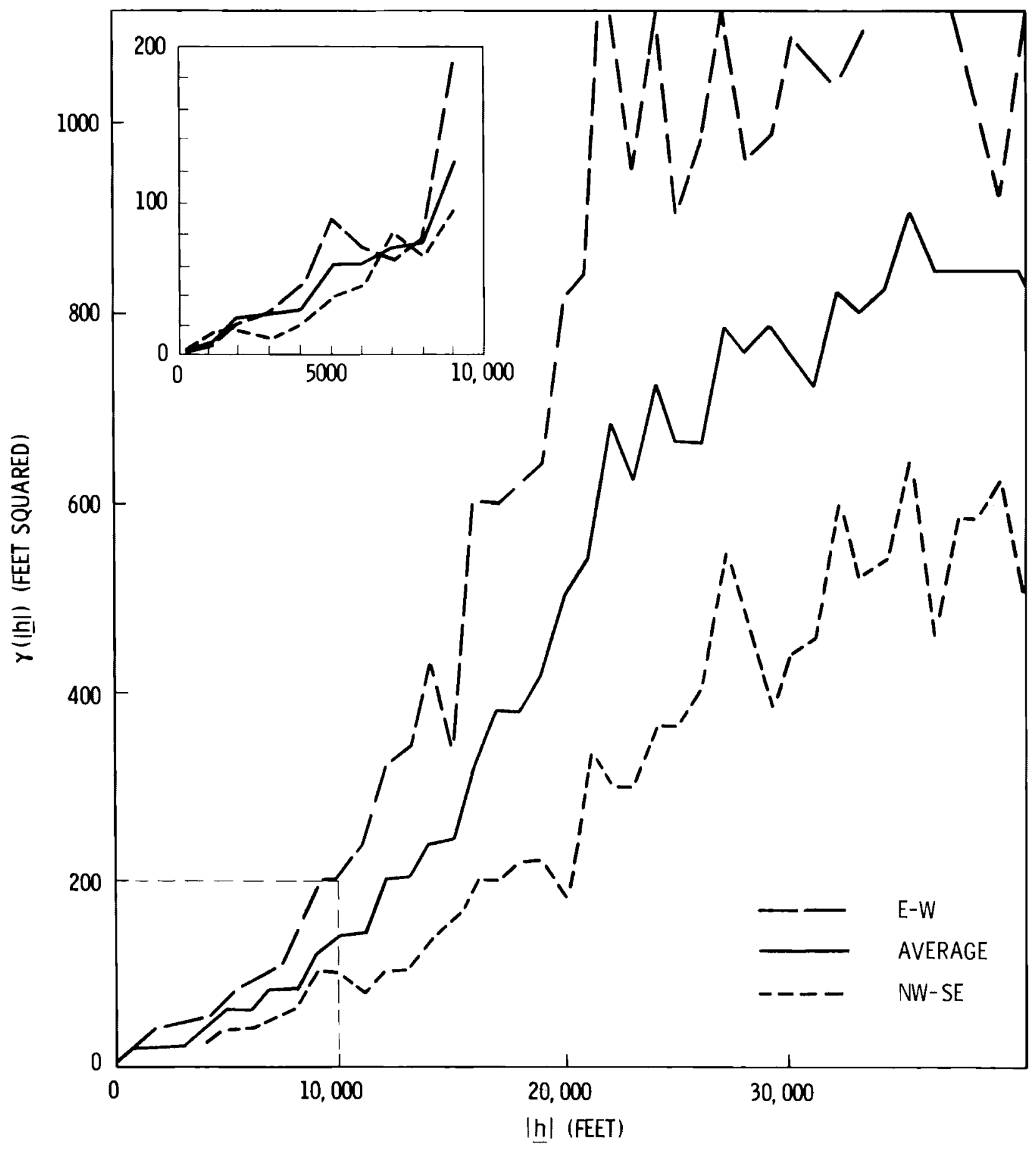

FIGURE 8

Directional and Average Empirical Variograms of September 1973 Hanford Water Elevations 
An automatic structure identification analys is was performed for the entire grid. It chose a linear drift and generalized function covariance with a linear and cubic component:

$$
K(|\underline{\mathrm{h}}|)=-.2648 E(-02)|\underline{\mathrm{h}}|+.3080 E(-10)|\underline{\mathrm{h}}|^{3} .
$$

This result is not inconsistent with the interpretation of the variograms. A separate structure identification analys is was performed on each of the four subgrids. All analyses identified a linear drift. The choice of covariance function, however, varied among the subgrids; the summary of the results is given in Table 2.

TABLE 2

$\begin{array}{ccc}\frac{\text { Grid }}{1} & \text { Location } & \\ 2 & \text { SW } & K(|\underline{h}|)=.1829 E(-08)|\underline{h}|^{3} \\ 3 & \text { SE } & K(|\underline{h}|)=-.2082 E(-01)|\underline{h}| \\ 4 & \text { NW } & K(|\underline{h}|)=-.2086 E(-02)|\underline{h}|+.5916 E(-10)|\underline{h}|^{3} \\ & \text { NE } & K(|\underline{h}|)=-.1379 E(-02)|\underline{h}|+.8082 E(-10)|\underline{h}|^{3}\end{array}$

Another analysis of Grid 4 yielded the covariance function

$$
K(|\underline{h}|)=-.5189 E(-02)|\underline{h}|+.2042 E(-09)|\underline{h}|^{3} .
$$

Although the choice of a covariance function is supposedly made robustly (not influenced unduly by extreme data values), the location of the data points within each of the grids and the data chosen to select the model exert their influence. Comparing these six covariance functions, a 
covariance with a linear and cubic component was selected four times. This generalized covariance function is consistent with the empirical variograms. Because of the consistency of the selected covariance functions, it was decided to try one covariance function for all four grids. The function,

$$
K(|\underline{h}|)=-.5189 E(-02)|\underline{h}|+.2042 E(-09)|\underline{h}|^{3} \text {, }
$$

was representative; the coefficients of the $|\underline{h}|$ terms makes 7 ittle difference in the grid estimates. The kriged contour map of the groundwater elevation using this covariance function is shown in Figure 9 . For comparison, the contour map of the same data produced by the Water and Land Resources Department from a digitized hand-drawn potential map is shown in Figure 10. The two maps are quite similar. The person drawing the potential map relies on substantive knowledge: behavior of a groundwater system and geology of the region. In contrast, the kriged contour estimates were produced only from the water potential data, without substantive knowledge of the phenomenon.

A contour map of the kriging standard errors (square root of the kriging variance) is shown in Figure 11. The standard error is less than 5 feet throughout most regions of the data and then gradually increases to the boundaries. This increasing trend reflects the fact that the boundary area grid point estimates must be made from data scattered over a large area than for the more centrally located gric points.

The interpretation of the map of standard errors (using a normal theory approximation) is that the true water potential surface lies within \pm 10 feet (two standard errors) of the kriged surface (and hv extension, the hand-drawn contour) $95 \%$ of the time. 


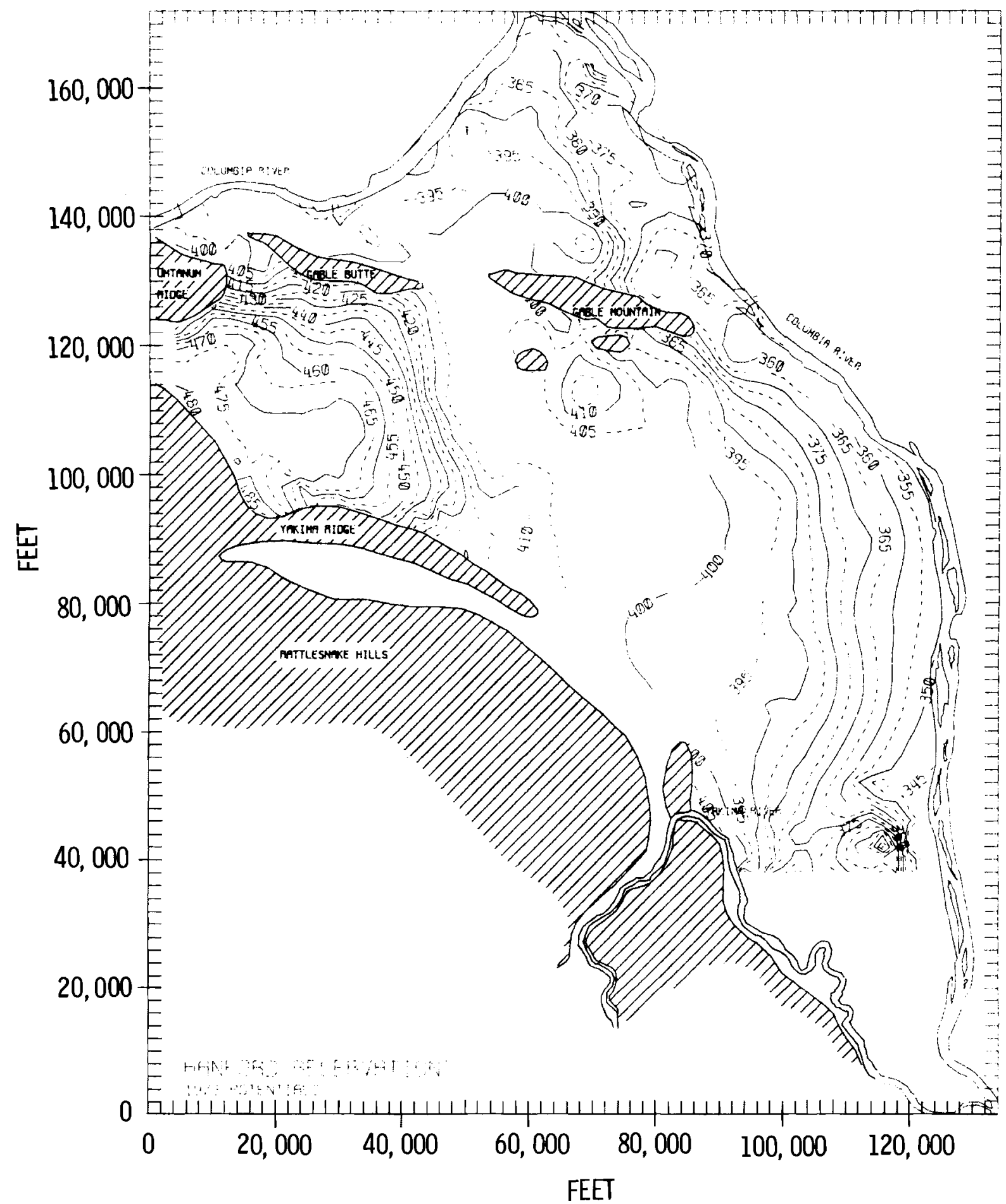

FIGURE 9

Kriged Contour Map of September 1973 Hanford Water Potential Surface 


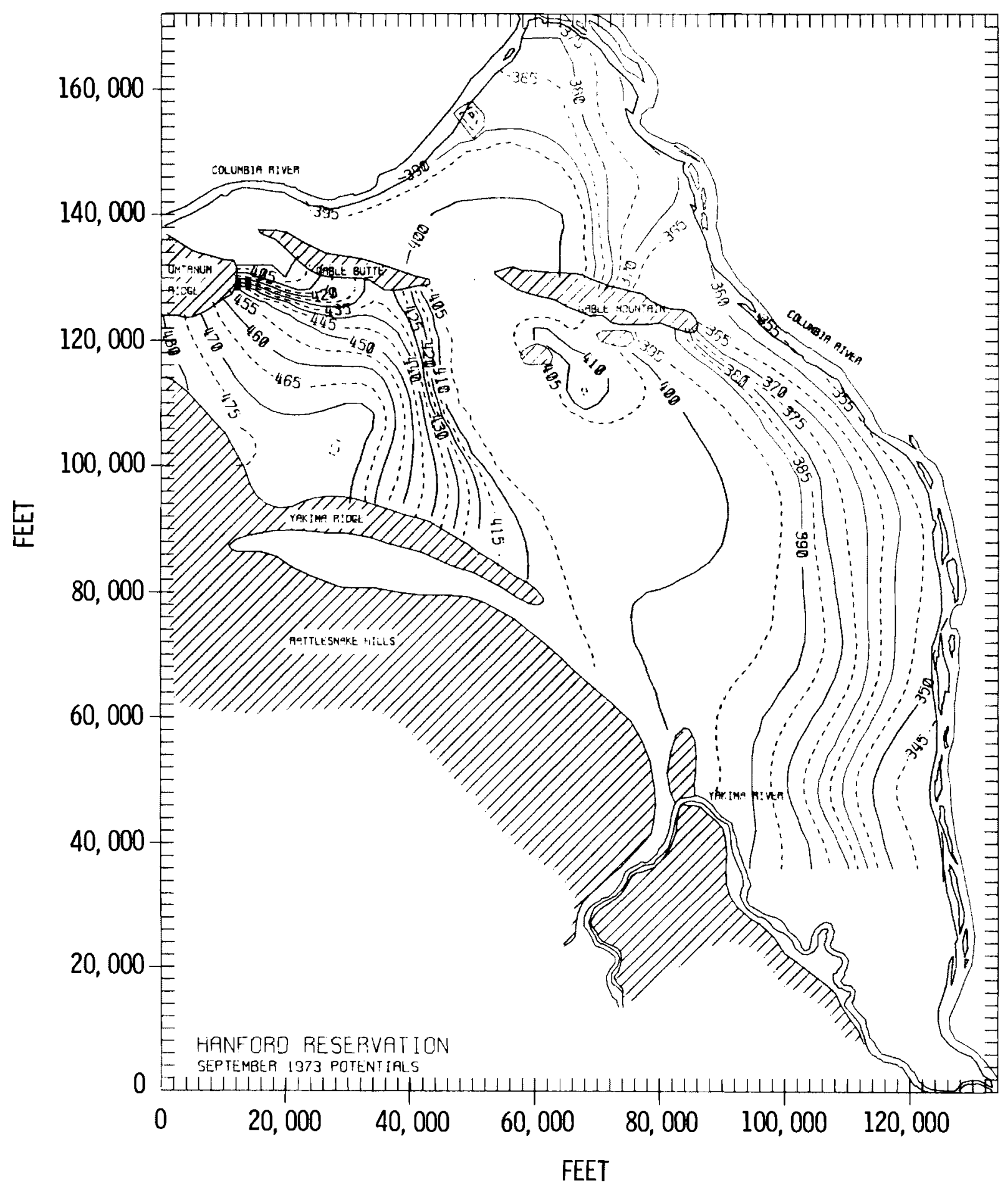

FIGURE 10

Hand-Drawn Contour Map of September 1973 Hanford Water Potential Surface 


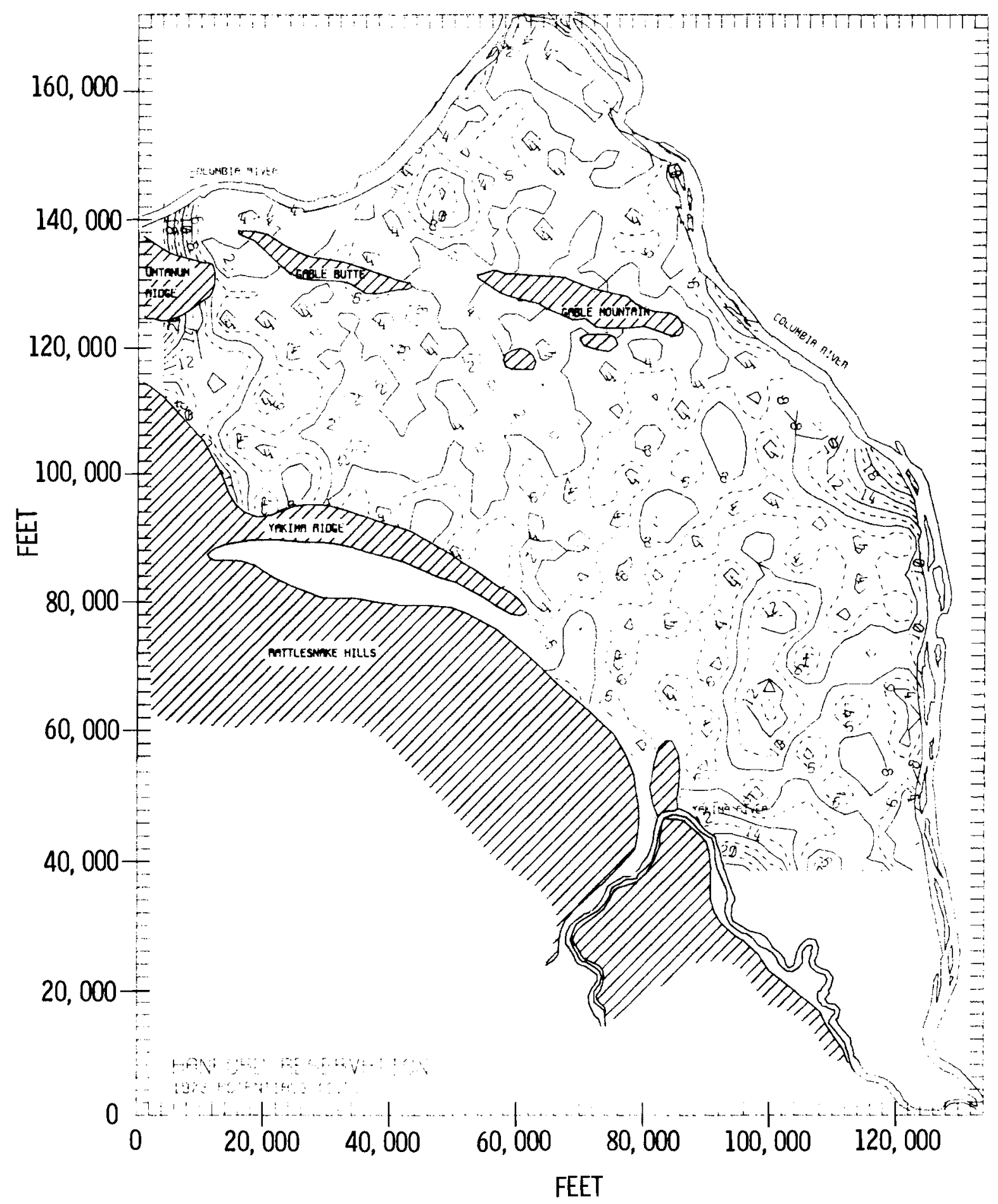

FIGURE 11

Contour Map of Kriging Standard Errors of September 1973 Hanford Water Potential Surface 
At any rate, 10 feet may seem excessively large at first considering the fact that at any one location the water potential can be measured with an error of a few hundredths of a foot. The kriging error is not just a measure of reproducibility, but a measure of the error in the surface at locations which have not been sampled. The kriged surface can be made to honor the data points, but there is no guarantee that the data are absolutely correct so the use of a filter to smooth the contours was used here. In any event, standard errors at the unsampled locations will still be of this order of magnitude. Since the kriging variance (and standard error) is only a function of the assumed variogram and data locations, the impact of a potential sampling location can be evaluated before that location is sampled. The optimum location is the one which produces the largest reduction in the kriging variance.

There is a strong caveat associated with the use of the kriging variance that applies as well to any statistical technique. These standard errors are realistic only if the chosen structure (order of the drift and covariance function) is a reasonable representation of the data. This can be checked in at least two ways:

1) Do the kriged contours look reasonable? If not, then the standard errors are meaningless.

2) Krige each of the data points and compare the estimate to the observed value. If the agreement is good, then again the standard errors are probably fairly accurate.

From a comparison with the hand-drawn contour which is considered the standard map, the kriged contours certainly pass the first test. A verification analysis using all of the data produced the observed errors,

$$
Z *(\underline{x})-Z(\underline{x})
$$


where $Z(\underline{x})$ is the observed value. These errors are divided by the kriging error $\sigma_{K}(\underline{x})$ to produce a standardized error

$$
\frac{Z *(\underline{x})-Z(\underline{x})}{\sigma_{K}(\underline{x})}
$$

The histograms of the errors and standardized errors are shown in Figures 12 and 13, respectively. Both are remarkably symmetric with respectively $6 \%$ and $9 \%$ of the absolute values of the error greater than 2.5 standard deviations, which is high for a normal distribution. Examination of a map of the standardized errors (Figure 14) can provide clues to the cause of the discrepancies. The letters and numbers represent intervals of 0.5 in the standard error scale; the legend is given under the map. The circled values represent absolute standardized errors greater than 3.00. They tend to cluster into three groups: along the Columbia River, Gable Mountain, and Yakima Ridge. The discrepancies are too systematically located to be caused entirely by incorrect data. The groundwater system for the area between Yakima Ridge and the Rattlesnake Hills acts nearly independently of the groundwater on the rest of the Site which can explain those deviations from the model. The groundwater system throughout most of the Site is an unconfined aquifer. However, the data set used to produce the kriged groundwater contours contains both confined and unconfined water measurements. The confined aquifers tend to be located in the areas of large deviation from the kriged model along the river and near Gable Mountain. Also, the water level in the river can fluctuate several feet due to the daily regulation of the power-generating Priest Rapids Dam located just upstream (ERDA-1538, p. II.3-D-4), which causes fluctuations in the water measurements in the nearby wells. These irregularities will be investigated more fully at a later date. 


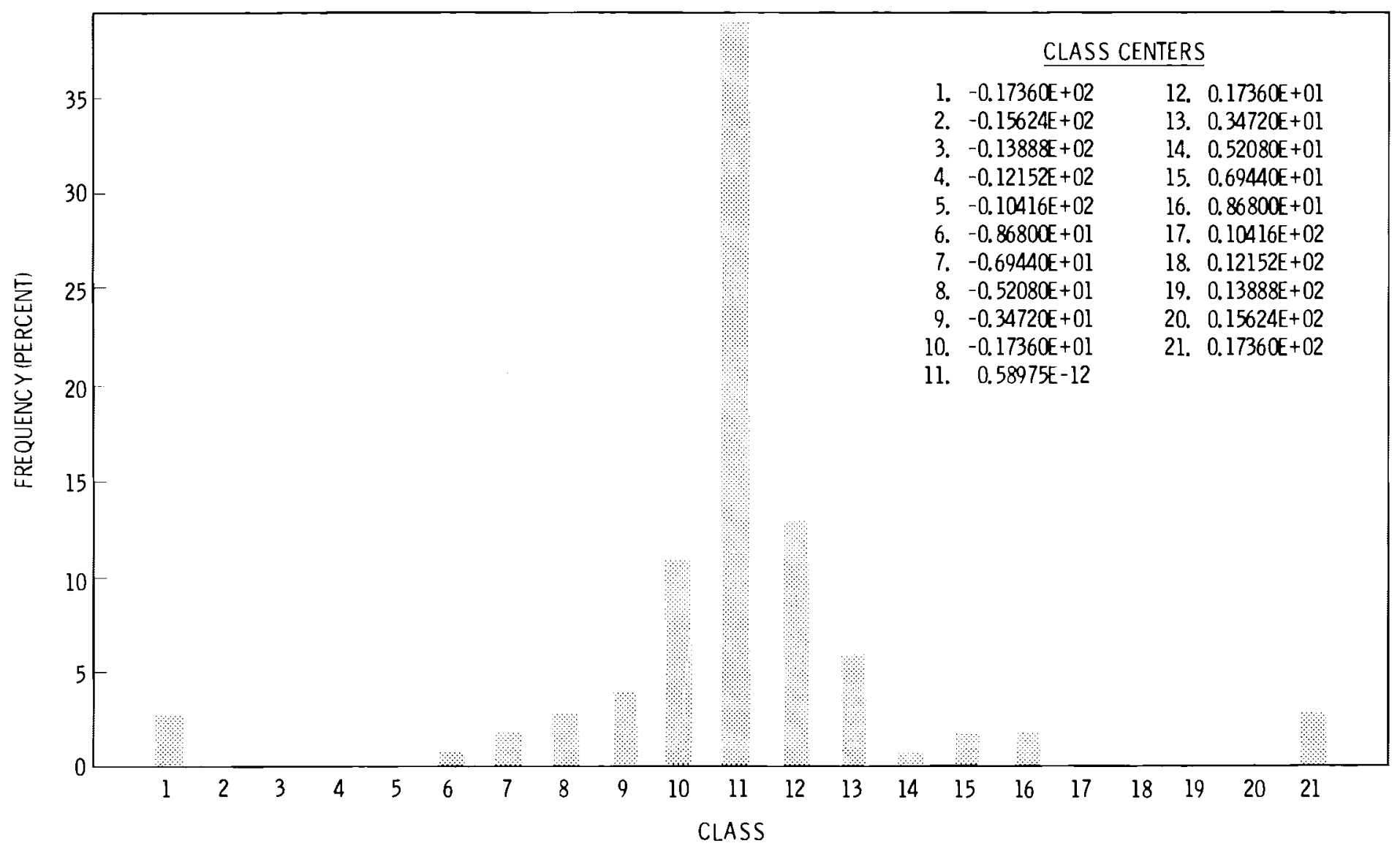

FIGURE 12

Histogram of the Actual Errors for the September 1973 Hanford Kriged Water Elevations 


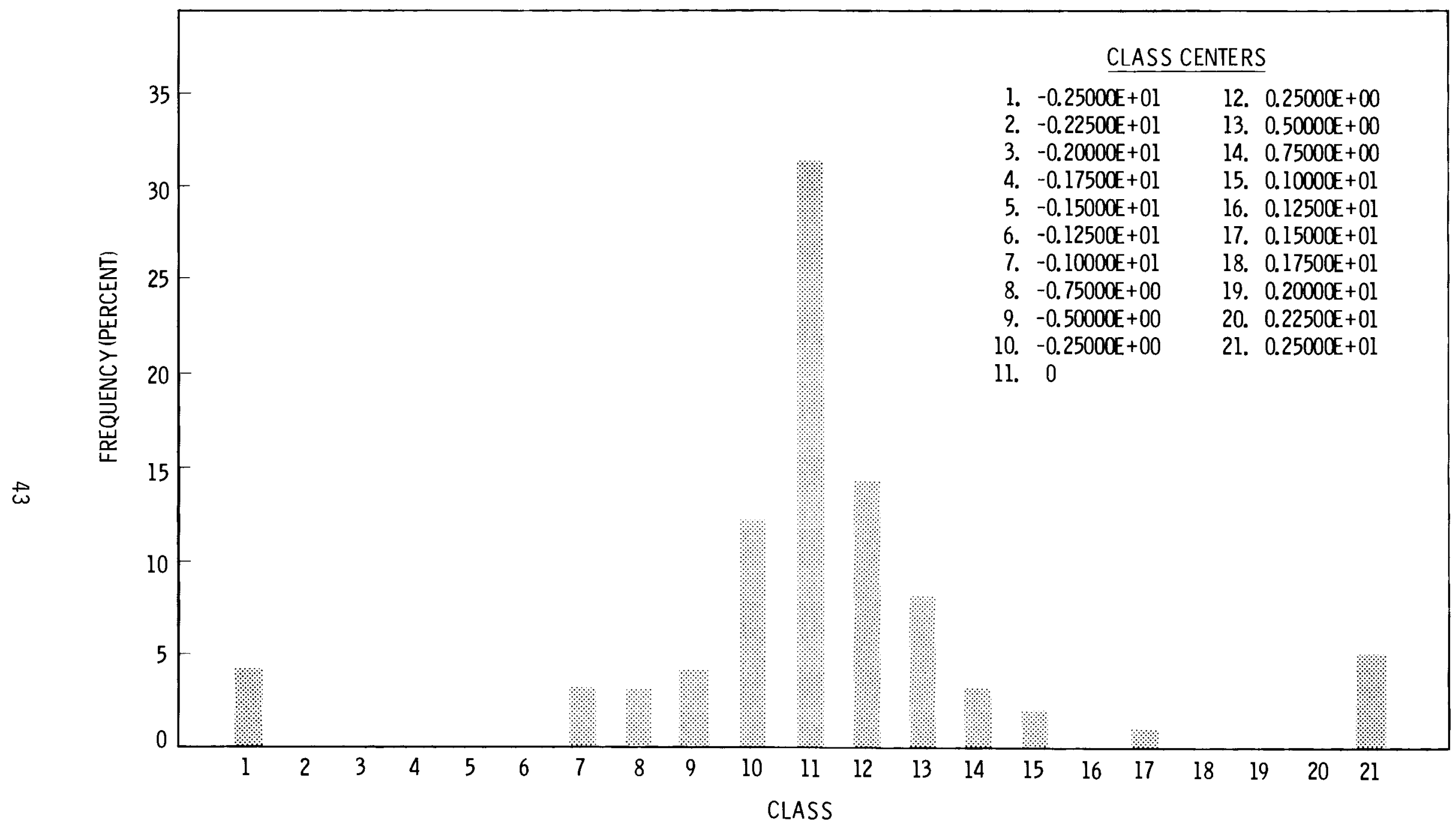

FIGURE 13

Histogram of Standardized Errors of the September 1973

Hanford Kriged Water Elevations 


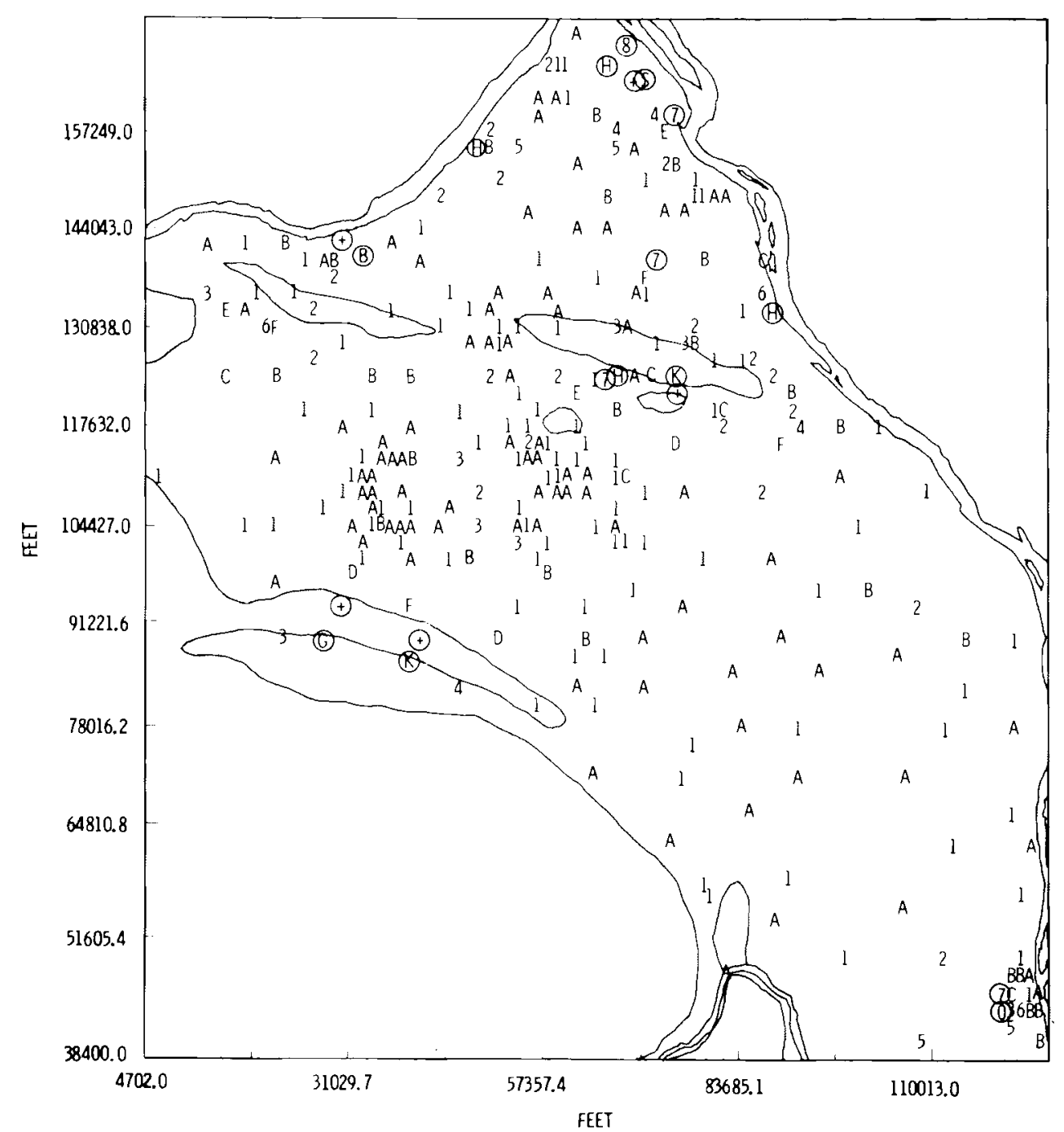

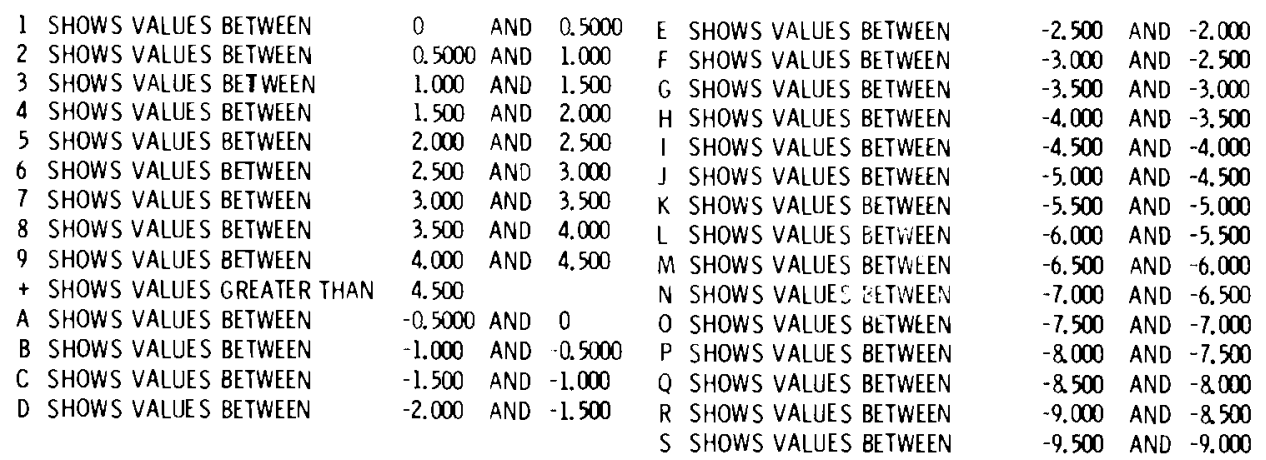

\section{FIGURE 14}

Map of Standardized Errors of September 1973 Hanford Kriqed Water Elevations 



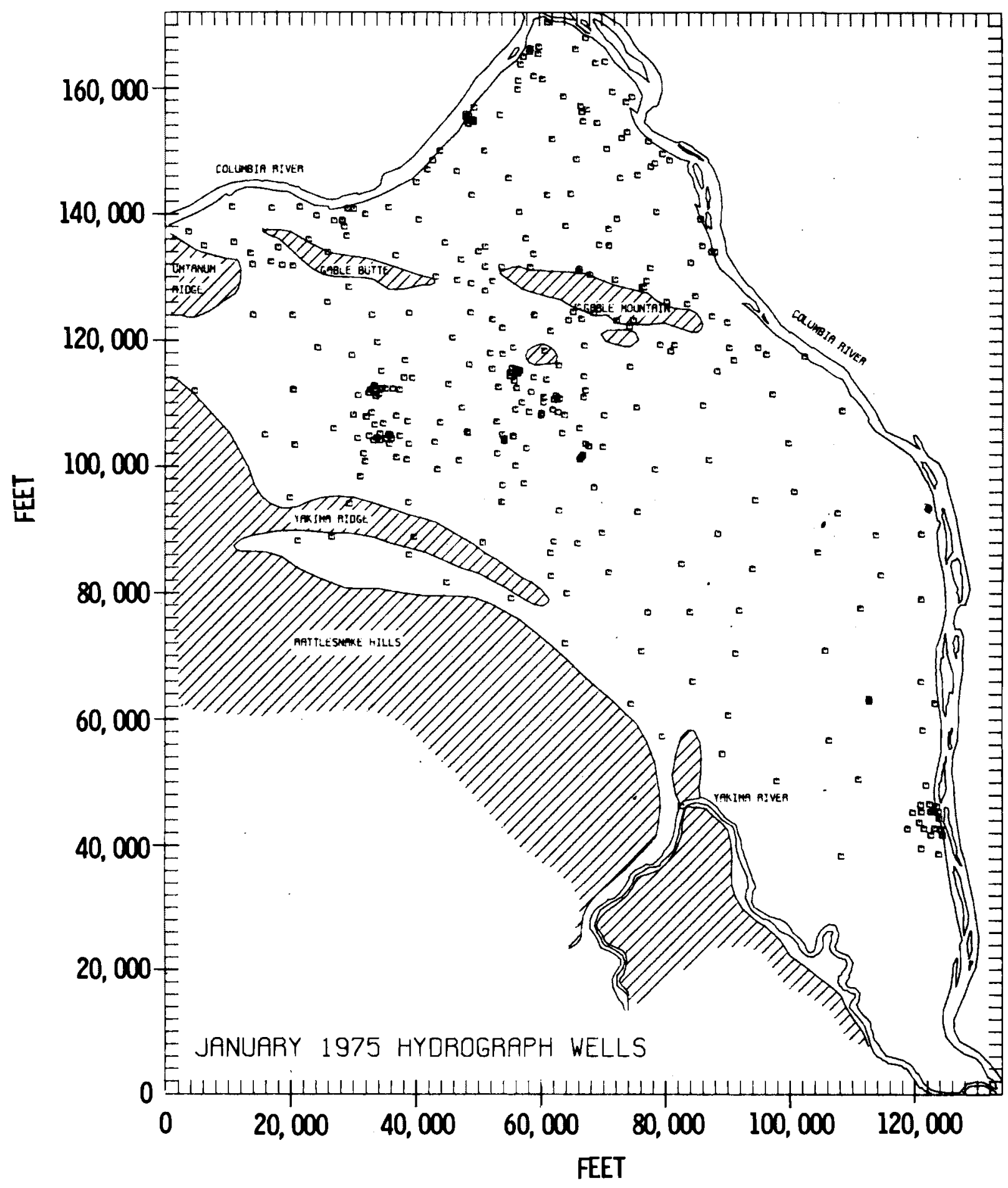

FIGURE 15

Locations of January 1975 Hanford Hydrograph Wells 


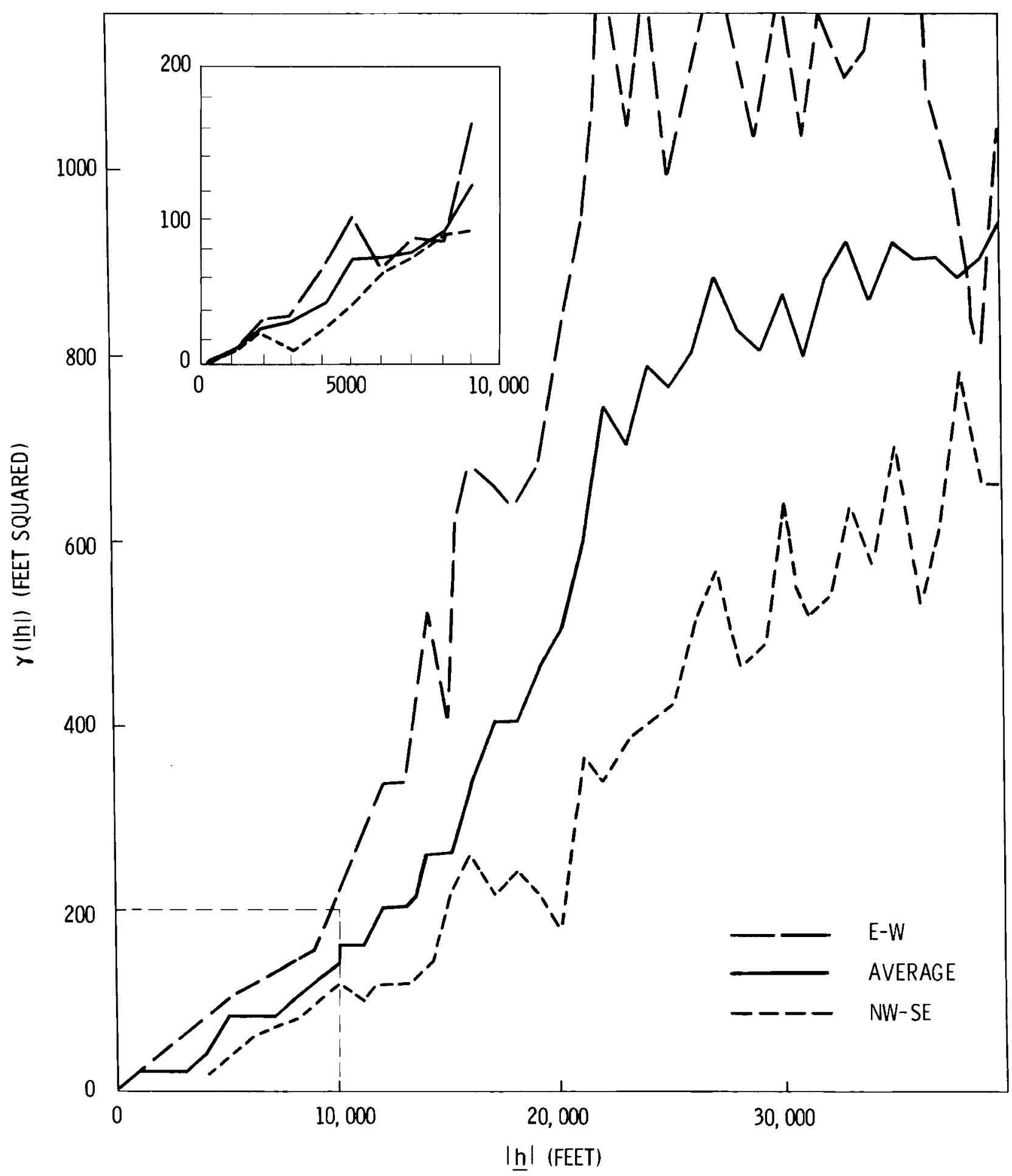

FIGURE 16

Directional and Average Empirical Variograms for January 1975 Hanford Water Elevations 


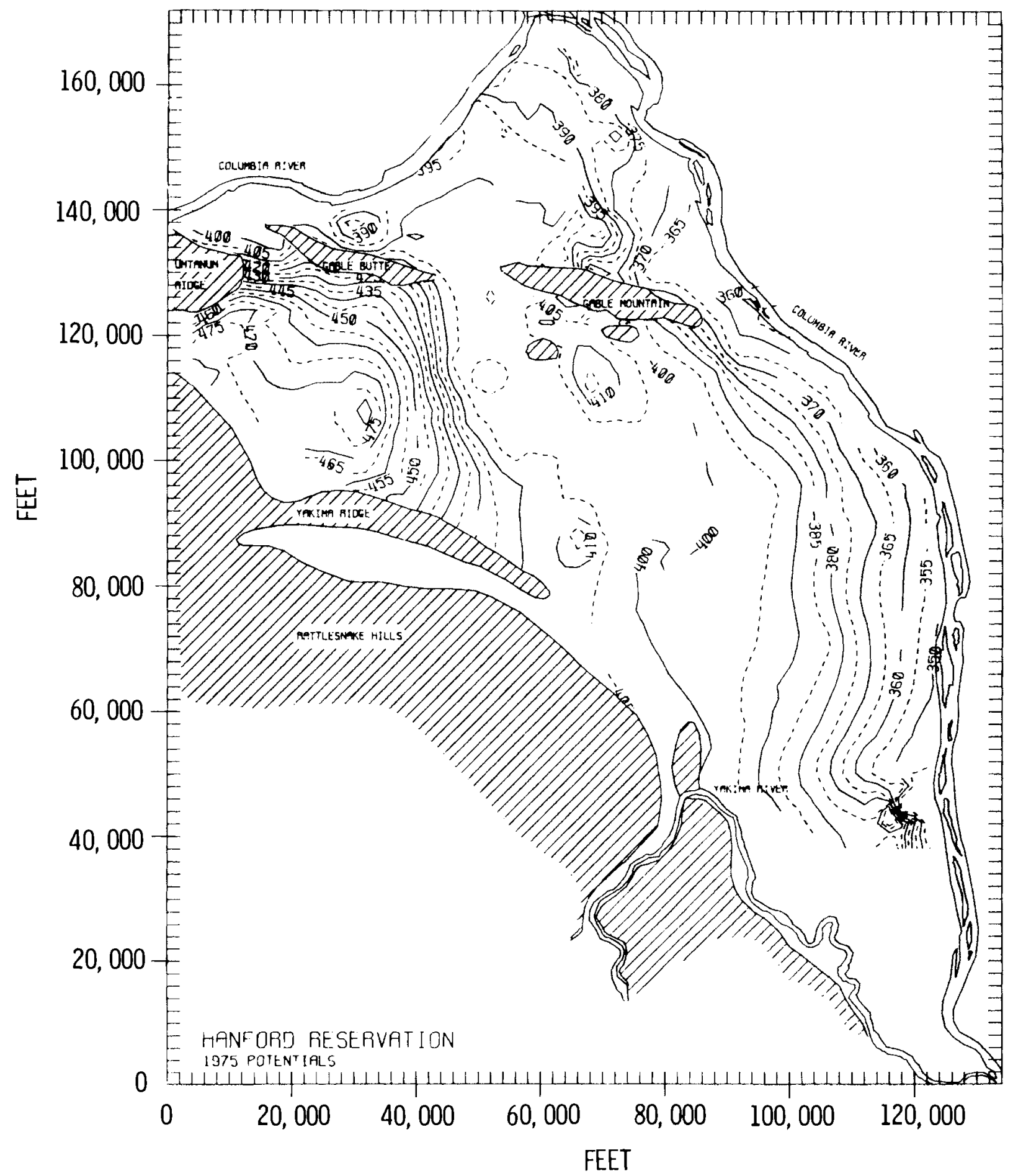

FIGURE 17

Kriged Contour Map of January 1975 Hanford Water Potential Surface 


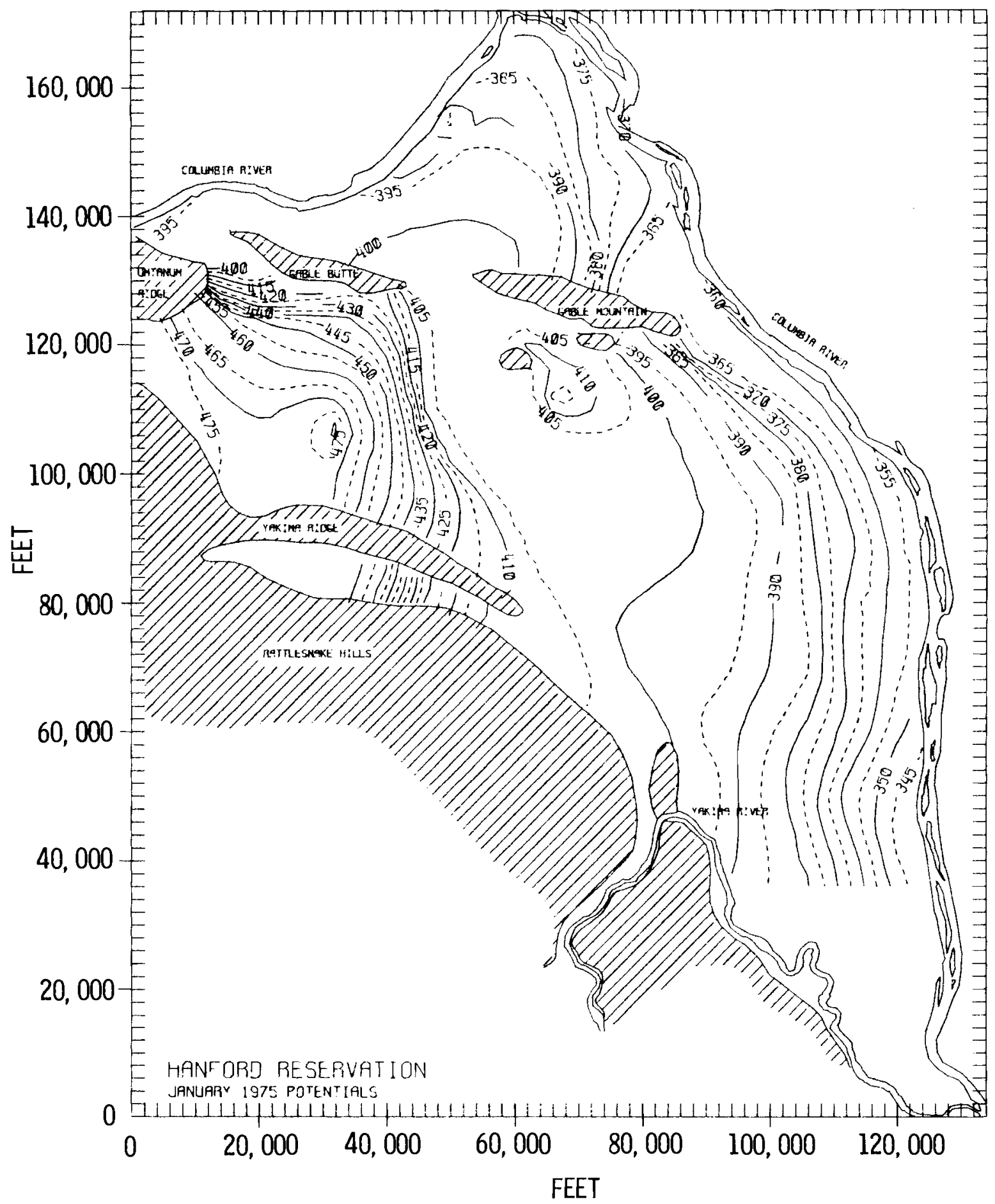

FIGURE 18

Hand-Drawn Contour Map of January 1975

Hanford Water Potential Surface 


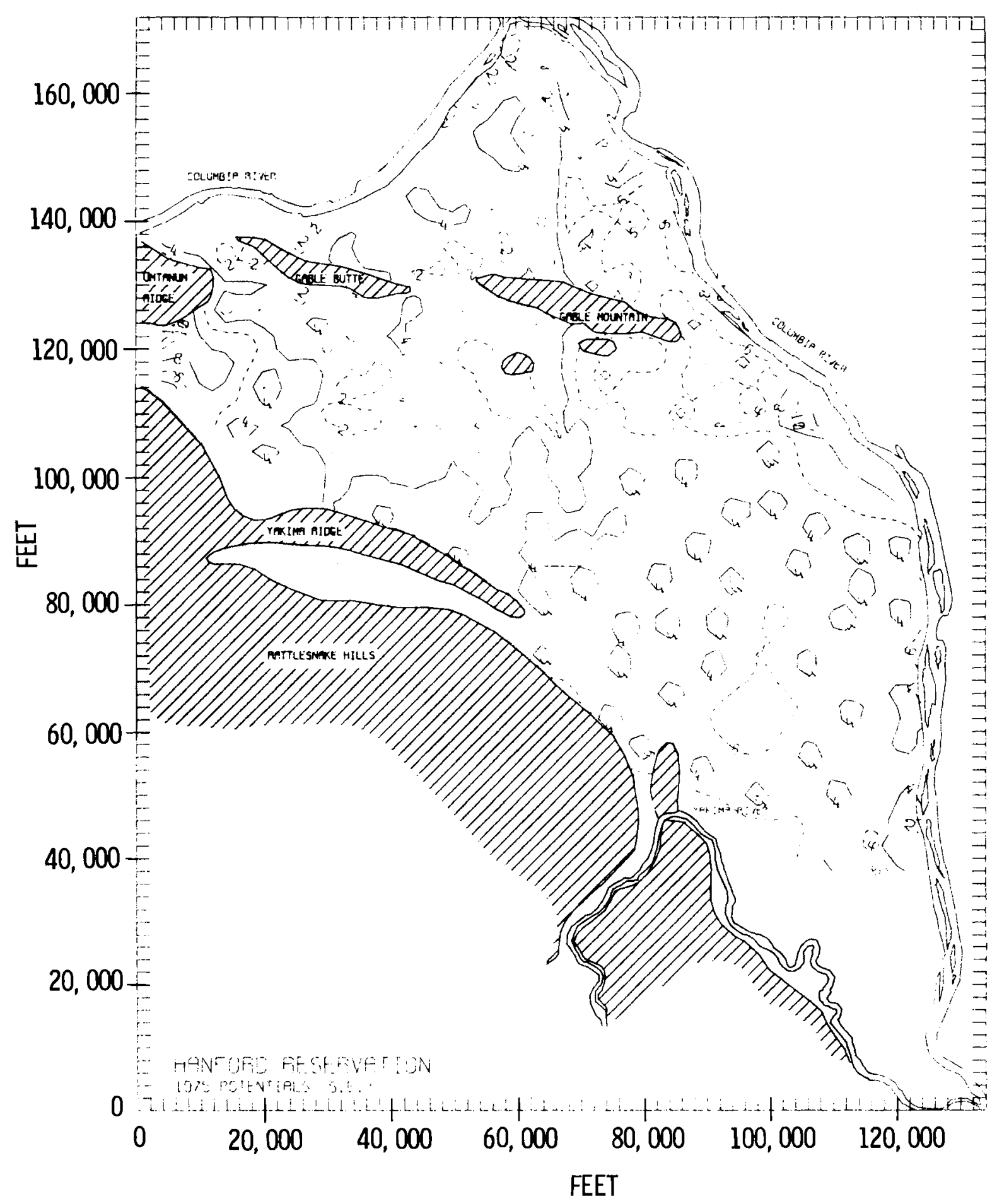

FIGURE 19

Contour Map of Kriging Standard Errors of January 1975 Hanford Water Potential Surface 



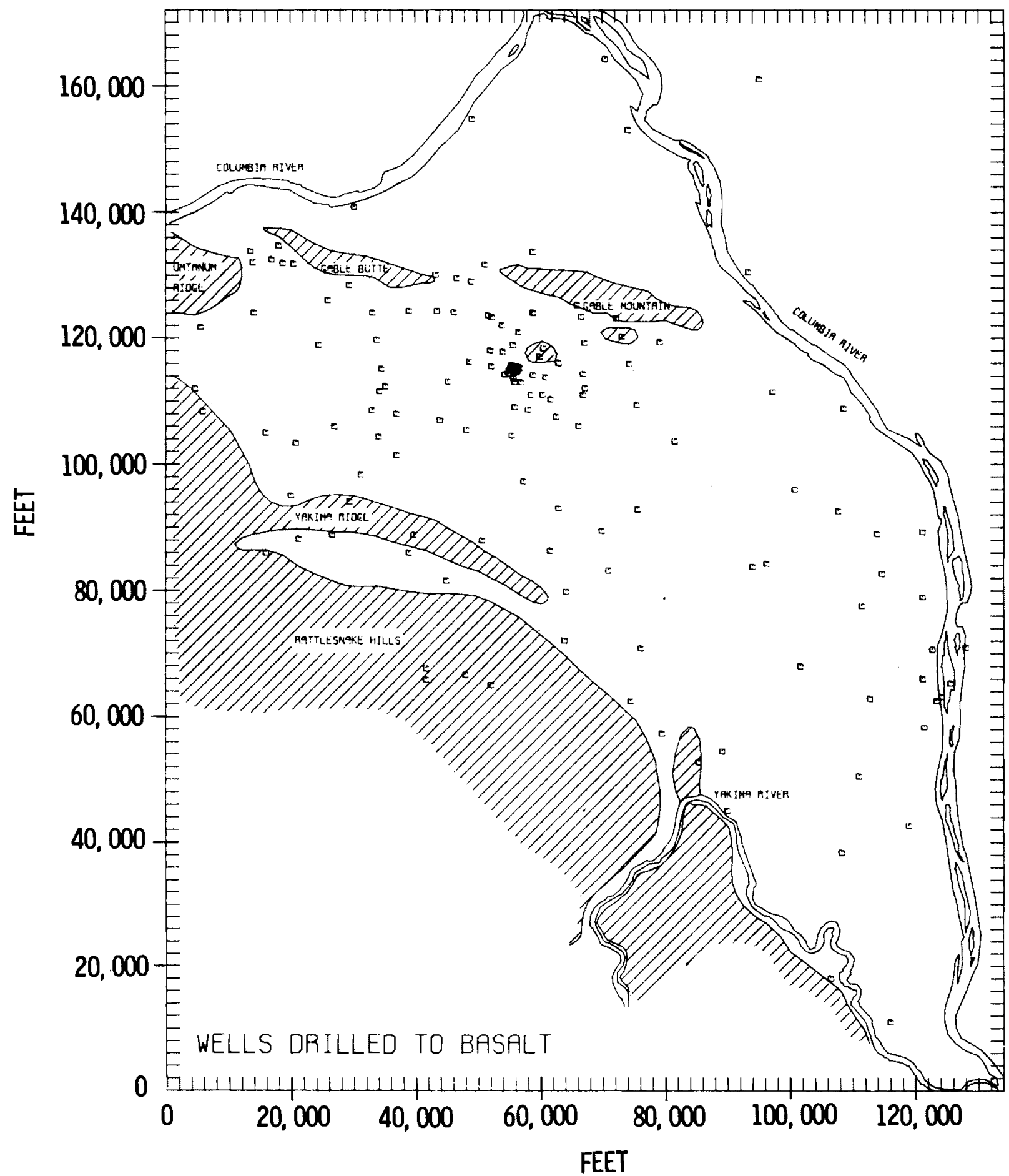

FIGURE 20

Locations of Wells Drilled into the Hanford Basalt Deposits 


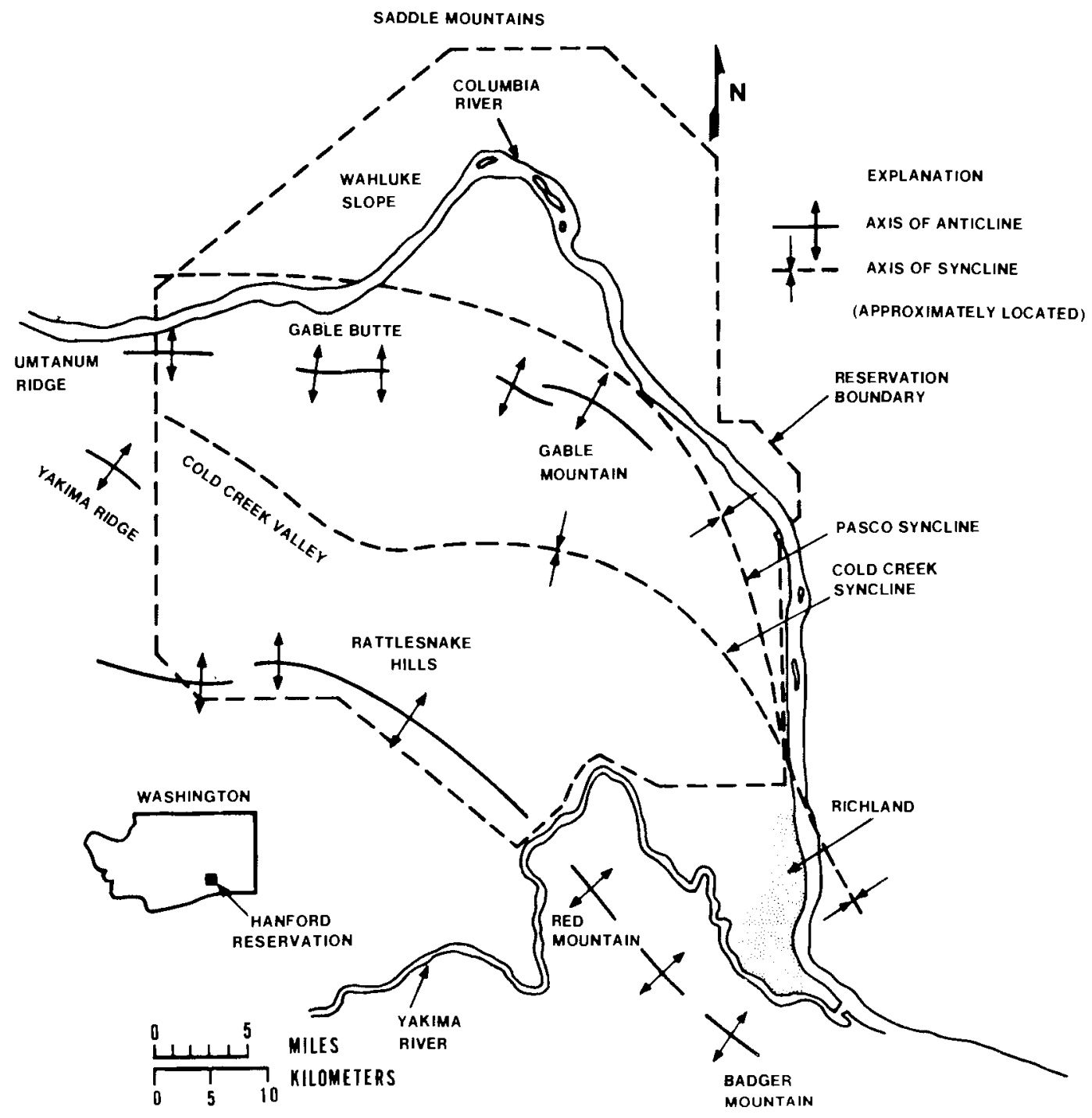

$\checkmark 7607 \cdot 13.18$

FIGURE 21

Locations of Major Basalt Synclines and Anticlines within the Hanford Reservation (After ARHCO, 1976) 


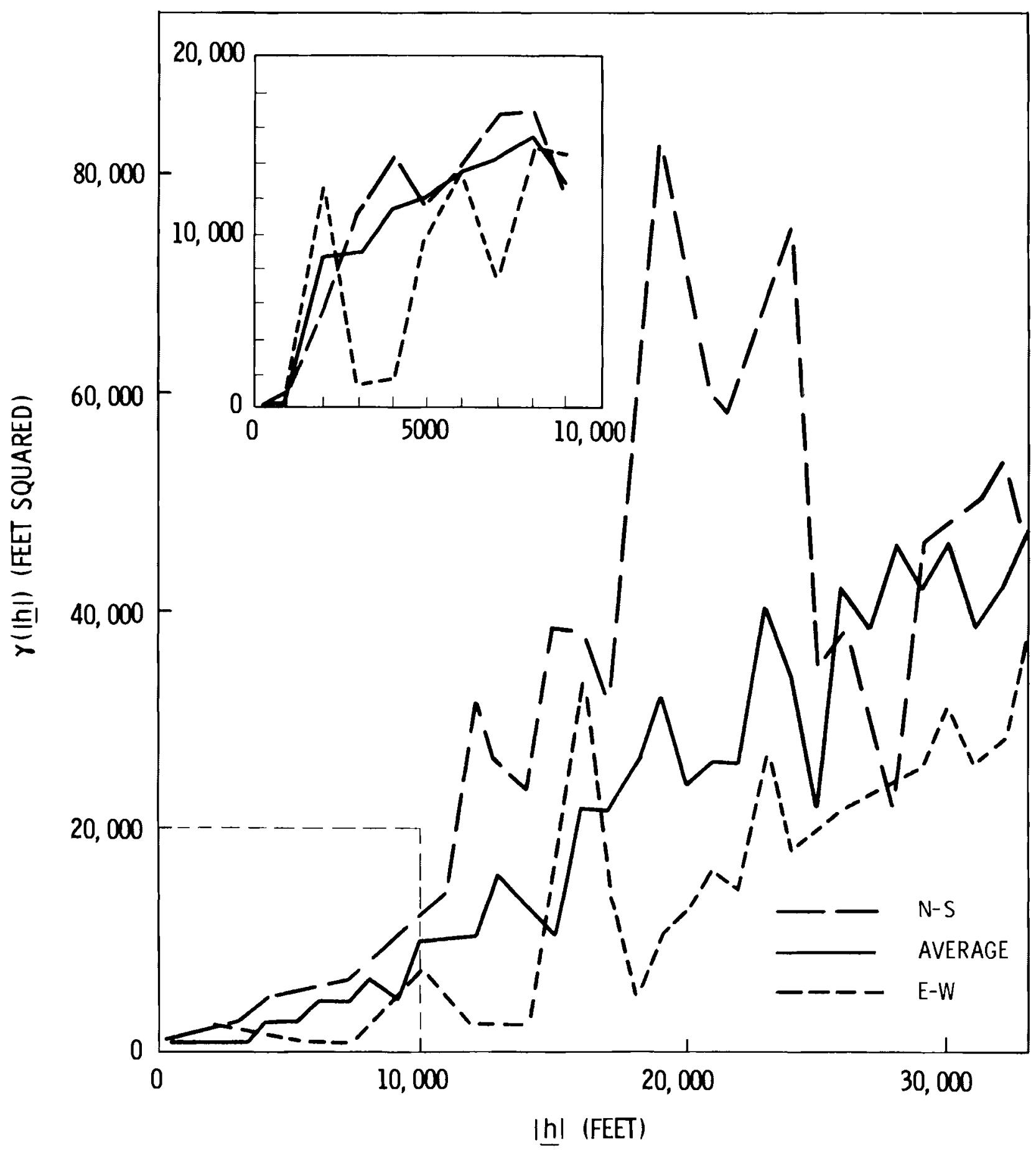

FIGURE 22

Directional and Average Empirical Variograms of Hanford Top-of-Basalt Elevations 
the basic form (convex curve with a leveling off at about 30,000 feet) is similar. One reason is the range of the data $(-216$ to 1250 feet above sea level) as compared to the water potentials (335 to 510 feet above sea level). This is reflected in the two orders of magnitude difference in the values of the two variograms throughout much of their range. The directional variograms do not show the separation seen for the water potentials; a partial explanation for this is the fewer number of data points. The rule of thumb used at the School of Mines is that one needs a minimum of 50 pairs of data points to have confidence in a single point of the empirical variogram. Most of the points defining the directional variograms are estimated with 30 or fewer data pairs. Because of the large fluctuations, the anisotrophies are not as apparent; however, the positions of the north-south and east-west variograms appear to be reversed. One explanation is the presence of the Pasco and Cold Creek synclines (Figure 21) which tend to run in an east-west direction across most of the Site until they near the river. An unexpected result is the small nugget effect ( 4.56 squared feet) considering the range of the data.

The variogram suggests basically the same covariance structure (presence of drift and a range of about 30,000 feet) as seen for the water potentials. The automatic structure identification analysis for all of the data selected a linear drift and a covariance structure,

$$
K(|\underline{h}|)=-.2839 E(-01)|\underline{h}|+.1639 E(-07)|\underline{h}|^{3}
$$

which is again similar to that of the water potential data but the coefficients are larger in absolute value. A verification analysis using the above structure reveals regions where the model did not perform well (Figure 23). The circled points represent discrepancies of greater than 


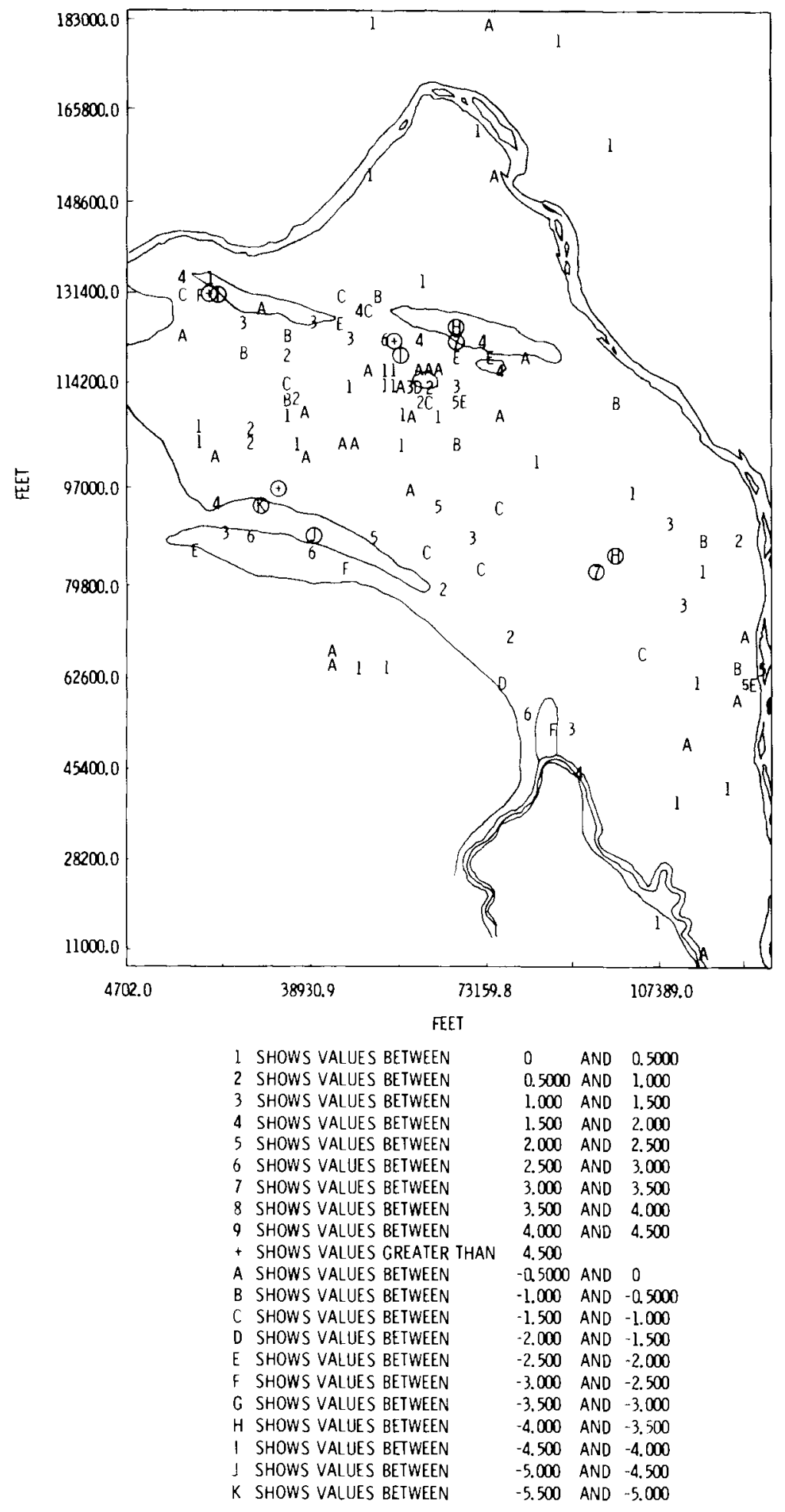

FIGURE 23

Map of Standardized Errors of Hanford Kriged Top-of-Basalt Elevations 
three standard error units. Comparing this to Figure 21 , these discrepancies tend to occur along the two synclines.

As for the water potentials, in order to contour the area bounded by the data using a grid size of 2000 feet square, the grid had to be quartered. Again for logistic reasons, the four subgrids were made of equal size.

Automatic structure identification analyses for each subgrid produced a larger variety of models than were seen for the water potential data. These models are given in Table 4.

TABLE 4

\begin{tabular}{|c|c|c|c|}
\hline Grid & Location & Drift & Covariance Function \\
\hline 1 & SW & linear & $K(|h|)=-3.862|h|$ \\
\hline 2 & SE & linear & $K(|\underline{h}|)=598.0-.9716|\underline{h}|+.7324 E(-10)|\underline{h}|$ \\
\hline 3 & NW & linear & $K(|\underline{h}|)=.4829 E(-08)|\underline{h}|^{3}$ \\
\hline 4 & NE & constant & $K(|\underline{h}|)=.1339 E(05)$ \\
\hline
\end{tabular}

The notable deviation from the pattern established for the water potential models is the model for Grid 4. The selected drift is a constant, and the covariance function chosen was a pure nugget. This is a very conservative model but it seems unrealistic. A partial explanation could be the result of the fact that Grid 4 contains few data points scattered over a large area, so that the data could appear to be unrelated. Although these models (except for Grid 4) honored the data within their grid range better than the model selected by all of the data, they smoothed the discontinuities in the basalt surface along the synclines. Discontinuities can be preserved 
by partitioning the area to be contoured into separate regions using the FAULT option for grid estimation. This prevents data on one side of a discontinuity from being used in the estimation of points on the other side. Certain trade-offs result from the use of the FAULT option because of the location of the data points with respect to the fault 1 ines. BLUEPACK is programmed to require between 8 and 16 data points to estimate a point. With the given fault lines, this may be impossible. Another problem is the distance that has to be covered to get the desired number of data points may become very large, resulting in very large kriging variances. A method to alleviate that situation is to require fewer data points, sometimes as few as two; this can be quite reasonable depending on the situation. In the case of the basalt, it seems more reasonable to use fewer highly-related data points to make an estimate than to go large distances to find less-related data for the sole purpose of satisfying a criteria for the minimum number of data points.

For this set of data, the fault lines were drawn for the Pasco and Cold Creek synclines referring to Figure 21 , but the final decision was based on the data. Automatic structure identification analyses for each grid were redone; the selected models are shown in Table 5.

TABLE 5

\begin{tabular}{cccc}
\hline Grid & Location & Drift & Covariance Function \\
1 & SW & cubic & $K(|\underline{h}|)=.1792 E(-07)|\underline{h}|^{3}$ \\
2 & SE & constant & $K(|\underline{h}|)=.2992 E(+05)$ \\
3 & NW & linear & $K(|\underline{h}|)=-.9598 E(-02)|\underline{h}|+.8073 E(-08)|\underline{h}|^{3}$ \\
4 & NE & linear & $K(|\underline{h}|)=-.1832|\underline{h}|+.3104 E(-08)|\mathrm{h}|^{3}$
\end{tabular}


Comparing these structures to the no-fault analyses in Table 4 shows a number of notable differences, among them the cubic drift for Grid 1 and the constant drift for Grid 2. Interestingly, the automatic structure identification chose a linear drift for Grid 4 . With the changes in estimated drift, the covariance functions also changed.

Structure selection does depend to a certain extent on the data points used for the analysis, although the selection procedure itself is based on fairly robust criteria. We experimented with other structures to observe the effect on the estimated contours. In particular, the selected structure for Grid 2, constant drift and constant covariance, did not seem reasonable. An imposed structure with constant drift and a 1 inear covariance $(K(|\underline{h}|=-1.339|\underline{h}|)$ produced more realistic contours.

After comparing the results of all of the analyses, the best contour map was judged to be the composite of the contours produced by the automatic structure identification analyses for Grids 1, 3, and 4 and an imposed constant drift and linear covariance for Grid 2. The plot of the top-of-basalt surface is given in Figure 24. Compare these contours to the basalt contours which are given in Lillie and Richard, 1977 (Figure 25). After some adjustments are made for differences in locations of the above-ground basalt deposits (Yakima Ridge and Rattlesnake Hills) between the two maps, they appear to be quite similar. The major features: an increasing trend at the Rattlesnake Hills, the Cold Creek syncline, and the depression between Gable Butte and Gable Mountain and the river, are readily apparent. The only real discrepancy is that the kriged contours have the Pasco syncline bisecting Gable Mountain. When the synclines were drawn for the kriging analyses, Figure 20 was not 


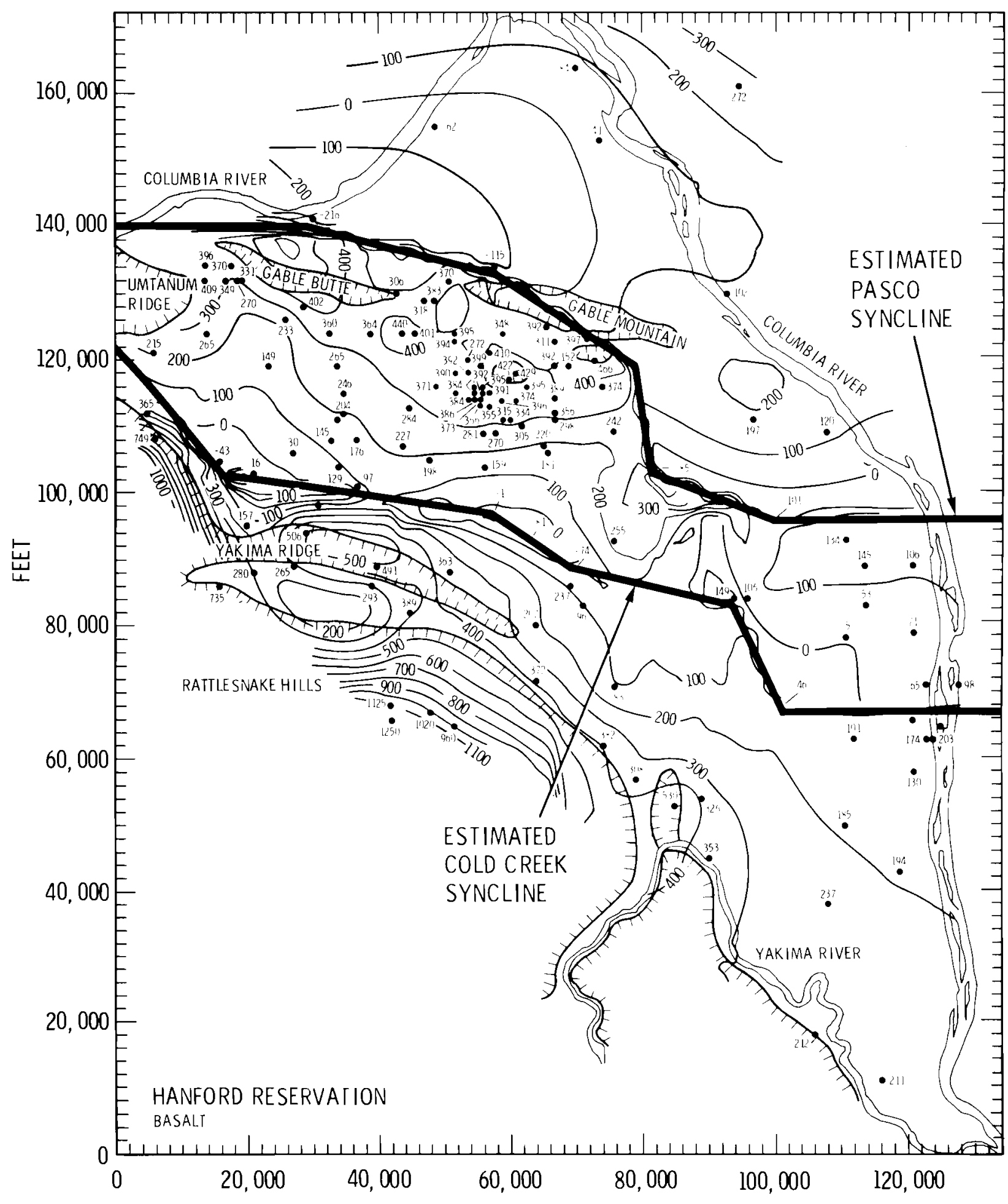

FEET

FIGURE 24

Kriged Contour Map of Hanford Top-of-Basalt Surface 


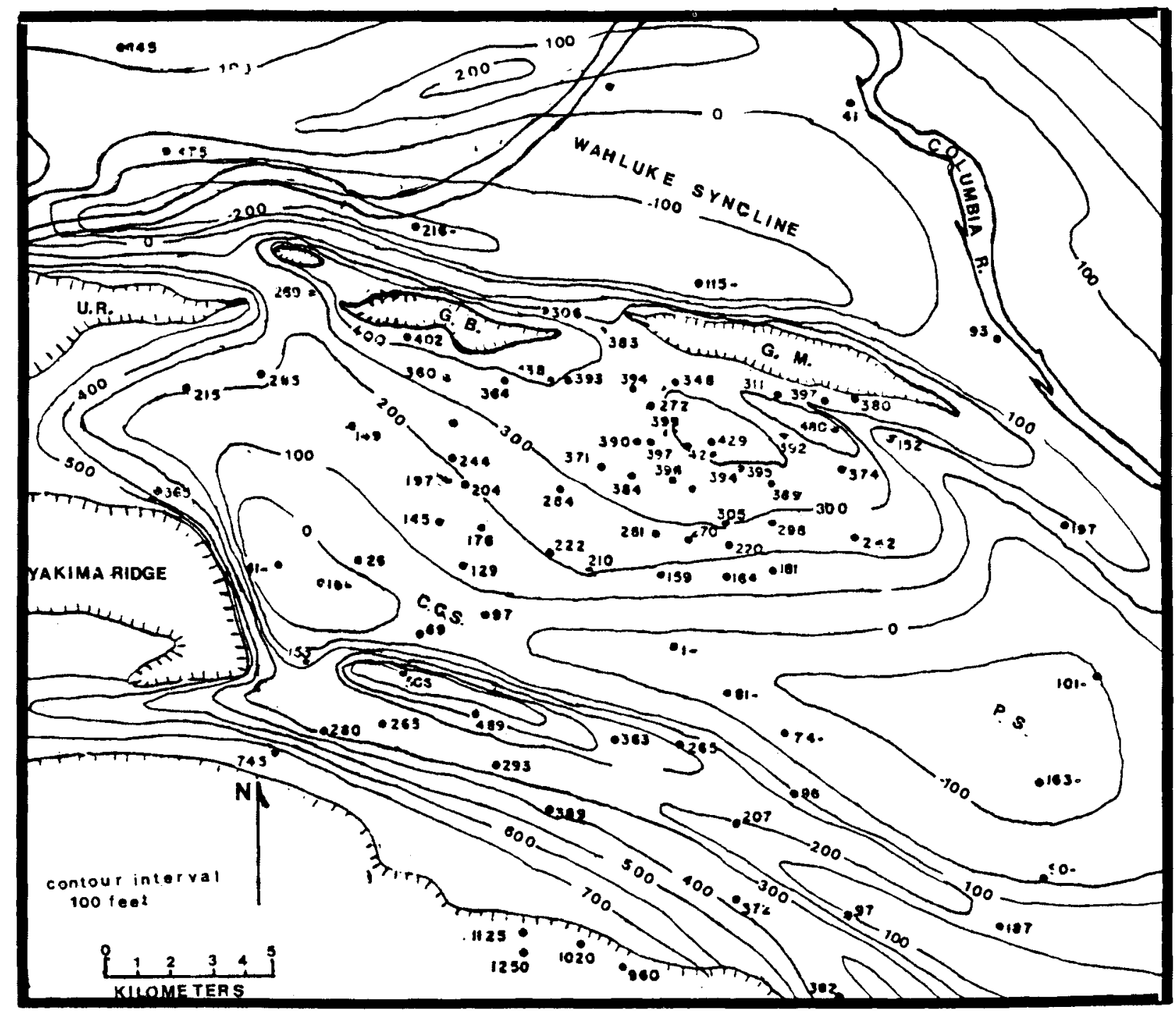

U.R. = Umtanum Ridge

G.B. = Gable Butte

G.M. = Gable Mountain

C.C.S. = Cold Creek Syncline

P.S. = Pasco Syncline

FIGURE 25

Structure Contour Map of the Top-Most Buried Basalt Surface

(From Lillie and Richard, 1977) 
available; with very little data near Gable Mountain, it was impossible to infer its exact location. It can be easily corrected, but since it would have little effect on the other contours, it was decided to leave it as it is for this report.

The contour map of the kriged standard errors is given in Figure 26 . The standard errors are generally an order of magnitude larger than those for the water potential data; this was expected from the magnitude of the variogram. The basalt surface at short distances is just not that well known, although for most of the Hanford Site, it is one continuous basalt flow (Elephant Mountain flow). An examination of Figure 4 in Lillie and Richard (1977) confirms what was observed from the data: The elevation of the top-most basalt layer can vary at least 40 feet over short distances. The kriged standard errors are usually larger than that, but they represent an average calculated over the entire region which includes irregularities caused by synclines, anticylines, and errosion.

It should be emphasized that the kriged contour of the top-of-basalt surface under the Hanford Site was not done to fulfill any purpose other than to try the kriging technique on a set of data in some sense typical of those from which site evaluation decisions will be made. For some purposes, for example, an overall view of the basalt surface, it may be adequate. However, if the purpose demands more resolution over a smaller area, say a 1000 foot radius, the currently available data are probably not sufficient to do it adequately with any contour estimation technique. However if more resolution is required, the contours will be improved by using the kriging variance, in conjunction with substantive knowledge, to optimize the locations of additional data.

\section{SUMMARY AND RECOMMENDATIONS}

The purpose of this study was to evaluate kriging techniques as a potential tool for geologic waste repository site characterization. We 


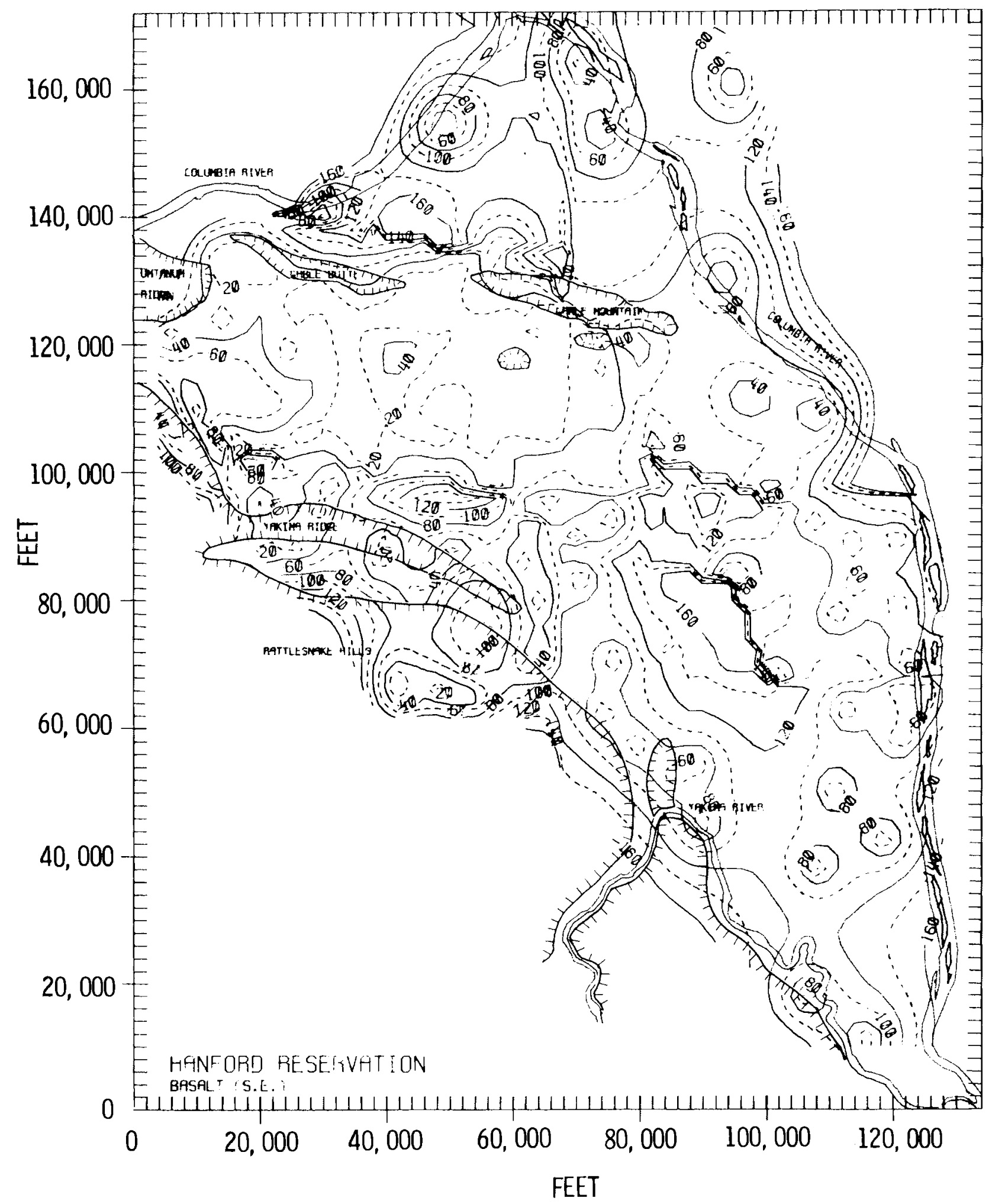

FIGURE 26

Contour Map of Kriging Standard Errors of Hanford Top-of-Basalt Surface 
believe they have demonstrated their usefulness for that purpose: they can produce realistic contours of a geologic phenomenon and an accompanying error, which can then be used to assess the accuracy of the contour. The kriging techniques (using the computer code BLUEPACK) were applied to water potential data and top-of-basalt elevations from the Hanford Site. The water potential contours were in close agreement with a handdrawn contour map which is used as a standard by PNL's Water and Land Resources Department. The basalt surface is very erratic and therefore not well known. However, the kriged contours appear to provide a realistic large-scale representation of the basalt surface that agrees rather well with the referenced contour maps.

These results are preliminary. They should in no way be considered as the best that can be produced from the kriging techniques. Kriging itself is in an evolutionary stage. Also, the work reported here made use of only data from drilled wells. In reality, much more information (data from gravity profiles and seismic readings, as well as substantive knowledge) would be used to generate a contour map or make decisions on the suitability of a potential site.

Kriging is a powerful mathematical and statistical tool for modeling geologic phenomena. As with any other spatial estimation technique, such as trend surface analysis, it can be used inappropriately. Kriging cannot be used blindly; as with any statistical tool, proper application requires an understanding of the assumptions underlying it and a thorough knowledge of its strengths and weaknesses. The work reported here is the beginning stage to attaining this knowledge and to developing kriging as a useful tool for site selection and characterization required for the licensing process. 
A general recommendation for kriging with respect to waste repository siting centers around its use in an interdisciplinary setting: all the people involved, geologists, physicists, chemists, and statisticians, interacting to develop an adequate characterization of a potential repository site from all of the available data. The work done to date and the availability of BLUEPACK make this feasible. In this interdisciplinary environment, more realistic empirical (kriging) models for a geologic site could be developed. In addition, the error analysis aspects of kriging theory can be used to evaluate the performance of deterministic physicallyderived models with respect to the data.

Specific technical recommendations to improve the contour estimates include:

1) the weighting oi data with respect to its accuracy or importance,

2) limiting the distance over which data are taken to calculate a grid estimate, and

3) gaining more experience in selecting and modeling sub-areas within a larger region; for example, the four subgrids within the Hanford Site.

Implementation of these points would contribute to increased understanding of the geologic structure underlying the Hanford Site. 


\section{REFERENCES}

Agterberg, F. P. 1974. Geomathematics. Elsevier Scientific Publishing Company, New York.

Akima, H. 1975. "Conments on 'Optimal Contour Mapping Using Universal Kriging' by Ricardo A. 0lea." Journal of Geophysical Research. $80(5): 832-836$.

ARHCO. 1976. Preliminary Feasibility Study on Storage of Radioactive Waste in Columbia River Basalts. Atlantic Richfield Hanford Company, Richland, WA 99352. Report ARH-ST-137.

Chiles, J. P. 1975. "How to Adapt Kriging to Non-Classical Problems: Three Case Studies." Advanced Geostatistics in the Mining Industry.

Davis, J. C. 1973. Statistics and Data Analysis in Geology. John Wiley and Sons, Inc., New York.

Delfiner, P. 1975. "Linear Estimation of Non-Stationary Spatial Phenomena." Advanced Geostatistics in the Mining Industry. Guarasco, M., M. David, and C. Huibregts, Eds. D. Reidel Publishing Company, Boston.

Delfiner, P. 1978. The Intrinsic Model of Order k. Center for Geostatistics, Paris School of Mines, 35 Rue Saint Honore, Fontainebleau, France. Report C-71.

Delfiner, P. and J. P. Delhomme. 1975. "Optimum Interpolation by Kriging." Display and Analysis of Spatial Data. Davis, J. C. and M. J. McCullagh, Eds. John Wiley and Sons, Inc., New York.

Final Environmental Statement, Waste Management Operations, Hanford Reservation, Richland, Washington. 1975. U.S. Energy Research and Development Administration. Report ERDA-1538.

Huijbregts, C. J. 1975. "Regionalized Variables and Quantitative Analysis of Spatial Data." Display and Analysis of Spatial Data. Davis, J. C. and M. J. McCullagh, Eds. John Wiley and Sons, Inc., New York.

Krige, D. K. 1966. "Two-Dimensional Weighted Moving Average Trend Surfaces for Ore Valuation." Journal of the South African Institute of Mining and Metallurgy. p. 13-79.

Lillie, J. J. and B. H. Richard. 1977. An Analysis of Selected Gravity Profiles on the Hanford Reservation Richland, Washington. Rockwell Hanford Operations, Richland, WA 99352. Report RHO-BWI-C-6.

Matheron, G. 1963. "Principles of Geostatistics." Economic Geology. 58: $1246-1266$. 


\section{REFERENCES (Cont'd.)}

Matheron, G. 1971. The Theory of Regionalized Variables and Its Applications. Centre for Mathematical Morphology, Paris School of Mines, Fontainebleau, France. Volume 5.

0lea, R. A. 1974. "Optimal Contour Mapping Using Universal Kriging." Journal of Geophysical Research. 79(5): 695-702.

Watson, G. S. 1972. Trend Surface Analys is and Spatial Correlation. Geological Society of America Special Paper 146. 


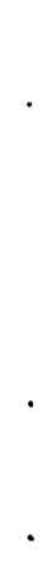




\section{APPENDIX}

The purpose here is to derive the conditions which lead to the kriging equations introduced in Section II.

Unbiasedness Condition

1) Constant Drift. Assume $E\left(Z\left(\underline{x}_{i}\right)\right)=m$ for $a 11 \underline{x}_{i}$, then

$$
\begin{aligned}
& E\left(Z *\left(\underline{x}_{0}\right)\right)=E\left(\sum_{i=1}^{N} \lambda_{i} Z\left(\underline{x}_{i}\right)\right) \\
& =\sum_{i=1}^{N} \lambda_{i} m=E\left(Z\left(\underline{x}_{0}\right)\right)=m .
\end{aligned}
$$

This implies that

$$
\sum_{i=1}^{N} \lambda_{i}=1,
$$

which is the unbiasedness condition.

2) Non-Constant Drift. Assume that the drift can be represented by a sum of monomials, $f^{\ell}\left(\underline{x}_{i}\right), \ell=0, \ldots, L$, so that $E(Z(\underline{x}))=\sum_{\ell} a_{\ell} f^{\ell}(\underline{x})$. The terms $a_{\ell}$ are constants. Then

$$
\begin{aligned}
E\left(Z^{*}\left(\underline{x}_{0}\right)\right) & =\sum_{i=1}^{N} \lambda_{i} E\left(Z\left(\underline{x}_{i}\right)\right)=\sum_{i=1}^{N} \lambda_{i} \sum_{\ell} a_{\ell} f^{l}\left(\underline{x}_{i}\right) \\
& =E\left(Z\left(\underline{x}_{0}\right)\right)=\sum_{l} a_{\ell} f^{l}\left(\underline{x}_{0}\right) .
\end{aligned}
$$

Interchanging sums yields

$$
\sum_{\ell} a_{\ell} \sum_{i=1}^{N} \lambda_{i} f^{\ell}\left(\underline{x}_{i}\right)=\sum_{\ell} a_{\ell} f^{\ell}\left(\underline{x}_{0}\right) .
$$


Since the $f^{\ell}(\cdot)$ are monomials, then for each $\ell, \sum_{j=1}^{N} \lambda_{i} f^{\ell}\left(\underline{x}_{j}\right)=f^{\ell}\left(\underline{x}_{0}\right)$. These are the unbiasedness conditions for the non-constant drift case.

\section{Minimum-Variance Condition}

In order to derive the kriging equations, it is usefur to have the relationship between the variogram and the covariance (when it exists) under the assumption of a constant drift. Recall that the variogram is defined as

$$
\begin{aligned}
2 \gamma\left(\left|\underline{x}_{i}-\underline{x}_{j}\right|\right) & =E\left(Z\left(\underline{x}_{i}\right)-Z\left(\underline{x}_{j}\right)\right)^{2}=\operatorname{Var}\left(Z\left(\underline{x}_{i}\right)-Z\left(\underline{x}_{j}\right)\right) \\
& +\left[E\left(Z\left(\underline{x}_{j}\right)-Z\left(\underline{x}_{j}\right)\right)\right]^{2} .
\end{aligned}
$$

Under the assumption of stationarity (constant drift)

$$
\begin{aligned}
2 \gamma\left(\left|\underline{x}_{j}-\underline{x}_{j}\right|\right) & =\operatorname{Var}\left(Z\left(\underline{x}_{j}\right)-Z\left(\underline{x}_{j}\right)\right) \\
& =\operatorname{Var}\left(Z\left(\underline{x}_{j}\right)\right)+\operatorname{Var}\left(Z\left(\underline{x}_{j}\right)\right)-2 \operatorname{Cov}\left(Z\left(\underline{x}_{j}\right), Z\left(\underline{x}_{j}\right)\right),
\end{aligned}
$$

and since we can assume that

$$
\operatorname{Cov}(\alpha, \beta)=C(\beta-\alpha)
$$

then

$$
2 x\left(\left|\underline{x}_{i}-\underline{x}_{j}\right|\right)=2 C(0)-2 C\left(\left|x_{i}-x_{j}\right|\right)
$$

Therefore,

$$
2 \gamma\left(\left|\underline{x}_{i}-\underline{x}_{j}\right|\right)=2\left(C(0)-c\left(\left|\underline{x}_{i}-\underline{x}_{j}\right|\right)\right)
$$

or

$$
r\left(\left|\underline{x}_{i}-\underline{x}_{j}\right|\right)=c(0)-c\left(\left|\underline{x}_{i}-\underline{x}_{j}\right|\right) .
$$


We desire the kriging estimate $Z^{*}\left(\underline{x}_{0}\right)$ at a point $\underline{x}_{0}$ to minimize the theoretical variance,

$$
\begin{aligned}
& \sigma^{2}=\operatorname{Var}\left(z *\left(\underline{x}_{0}\right)-z\left(\underline{x}_{0}\right)\right) \\
& =\operatorname{Var}\left(Z^{*}\left(\underline{x}_{0}\right)\right)-2 \operatorname{Cov}\left(Z *\left(\underline{x}_{0}\right), Z\left(\underline{x}_{0}\right)\right) \\
& +\operatorname{Var}\left(Z\left(\underline{x}_{0}\right)\right) \\
& =\operatorname{Var}\left(\sum_{i=1}^{N} \lambda_{i} Z\left(\underline{x}_{i}\right)-2 \operatorname{Cov}\left(\sum_{i=1}^{N} \lambda_{i} Z\left(\underline{x}_{i}\right), Z\left(\underline{x}_{0}\right)\right)\right. \\
& +\operatorname{Var}\left(Z\left(\underline{x}_{0}\right)\right) \\
& =\sum_{j=1}^{N} \sum_{j=1}^{N} \lambda_{i} \lambda_{j} \operatorname{Cov}\left(z\left(\underline{x}_{i}\right), z\left(\underline{x}_{j}\right)\right) \\
& -2 \sum_{j=1}^{N} \lambda_{i} \operatorname{Cov}\left(z\left(\underline{x}_{j}\right), z\left(\underline{x}_{0}\right)\right)+\operatorname{Cov}\left(z\left(\underline{x}_{0}\right), z\left(\underline{x}_{0}\right)\right) \\
& =\sum_{j=1}^{N} \sum_{j=1}^{N} \lambda_{i} \lambda_{j}\left[C(0)-\gamma\left(\left|\underline{x}_{i}-\underline{x}_{j}\right|\right)\right] \\
& -2 \sum_{i=1}^{N} \lambda_{i}\left[C(0)-\gamma\left(\underline{x}_{i}-\underline{x}_{0}\right)\right]+C(0) \\
& =-\sum_{j=1}^{N} \sum_{j=1}^{N} \lambda_{i} \lambda_{j} \gamma\left(\underline{x}_{i}-\underline{x}_{j}\right) \\
& +2 \sum_{i=1}^{N} \lambda_{i} r\left(\left|\underline{x}_{i}-\underline{x}_{0}\right|\right) \text {. }
\end{aligned}
$$


Since the coefficients $\lambda_{i}$ are the only terms in Equation (A-1) not fixed, we minimize $\sigma^{2}$ with respect to $\lambda_{i}$ subject to the constraints of the unbiasedness conditions

$$
\sum_{i=1}^{N} \lambda_{i} f^{\ell}\left(\underline{x}_{i}\right)=f^{\ell}\left(\underline{x}_{0}\right), \ell=0, \ldots, L
$$

The function to be minimized by the Lagrange multiplier method is

$$
\begin{aligned}
Q= & \sigma^{2}+\sum_{\ell=0}^{L} \mu_{\ell}\left(\sum_{i=1}^{N} \lambda_{i} f^{\ell}\left(\underline{x}_{i}\right)-f^{\ell}\left(\underline{x}_{0}\right)\right) \\
= & 2 \sum_{i=1}^{N} \lambda_{i} \gamma\left(\left|\underline{x}_{i}-\underline{x}_{0}\right|\right)-\sum_{i=1}^{N} \sum_{j=1}^{N} \lambda_{i} \lambda_{j} \gamma\left(\left|\underline{x}_{i}-\underline{x}_{j}\right|\right) \\
& -2 \sum_{\ell=0}^{L} \mu_{\ell}\left(\sum_{i=1}^{N} \lambda_{i} f^{\ell}\left(\underline{x}_{i}\right)-f^{\ell}\left(\underline{x}_{0}\right)\right) .
\end{aligned}
$$

By taking partial derivatives with respect to each of the parameters $\lambda_{i}, i=1, \ldots, N$ and Lagrange multipliers $\mu_{\ell}, \ell=0, \ldots, L$ and equating them to zero, we obtain $N+L+1$ linear equations of the form

$$
\begin{gathered}
\frac{\partial Q}{\partial \lambda_{i}}=\gamma\left(\left|\underline{x}_{i}-\underline{x}_{0}\right|\right)-\sum_{j=1}^{N} \lambda_{j} \gamma\left(\left|\underline{x}_{i}-\underline{x}_{j}\right|\right)-\sum_{\ell=0}^{L} \mu_{\ell} f^{\ell}\left(\underline{x}_{i}\right)=0 \\
i=1, \ldots, N \\
\frac{\partial Q}{\partial \mu_{\ell}}=\sum_{i=1}^{N} \lambda_{i} f^{\ell}\left(\underline{x}_{j}\right)-f^{\ell}\left(\underline{x}_{0}\right)=0 . \\
\ell=0, \ldots, L
\end{gathered}
$$


By rearranging terms and recalling that $\gamma(0)=0$ and then expressing the equations in matrix form,

$$
\underline{A} \Lambda=\underline{\Gamma},
$$

the structure of the equations for $L=2$ becomes clear:

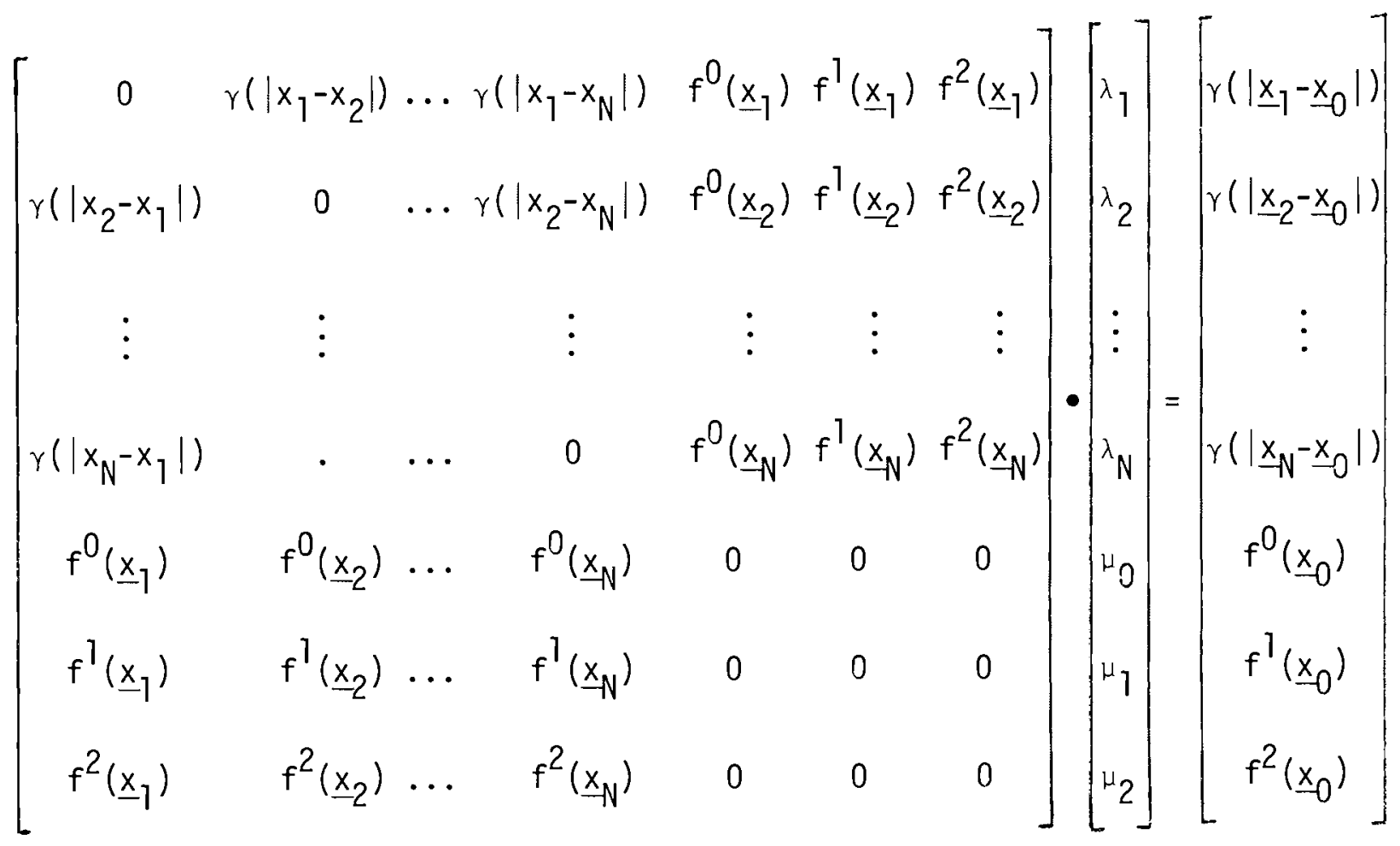

The values of $\lambda_{j}$ and $\mu_{\ell}$ which minimize are obtained from the solution of this system of linear equations,

$$
\underline{\Lambda}=\underline{A}^{-1} \underline{\Gamma} .
$$

To see the structure of the $\lambda_{j}{ }^{\prime} s$, assume for exposition purposes that $N=2$ and $L=0$. The system of Equations $(A-2)$ is

$$
\left[\begin{array}{ccc}
0 & \gamma\left(\left|\underline{x}_{1}-\underline{x}_{2}\right|\right) & 1 \\
\gamma\left(\left|\underline{x}_{1}-\underline{x}_{2}\right|\right) & 0 & 1 \\
1 & 1 & 0
\end{array}\right] \cdot\left[\begin{array}{c}
\lambda_{1} \mid \\
\lambda_{2} \mid \\
\mu_{0}
\end{array}\right]=\left[\begin{array}{c}
\gamma\left(\left|\underline{x}_{1}-\underline{x}_{0}\right|\right) \\
\gamma\left(\left|\underline{x}_{2}-\underline{x}_{0}\right|\right) \\
1
\end{array}\right] .
$$


The solution is given by

$$
\underline{\Lambda}=\frac{1}{2 \gamma\left(\left|\underline{x}_{1}-\underline{x}_{2}\right|\right)}\left[\begin{array}{ccc}
-1 & 1 & \gamma\left(\left|\underline{x}_{1}-\underline{x}_{2}\right|\right) \\
1 & -1 & \gamma\left(\left|\underline{x}_{1}-\underline{x}_{2}\right|\right) \\
\gamma\left(\left|\underline{x}_{1}-\underline{x}_{2}\right|\right) & \gamma\left(\left|\underline{x}_{1}-\underline{x}_{2}\right|\right) & -\gamma^{2}\left(\left|\underline{x}_{1}-\underline{x}_{2}\right|\right)
\end{array}\right] \cdot\left[\begin{array}{c}
\gamma\left(\left|\underline{x}_{1}-\underline{x}_{0}\right|\right) \\
\gamma\left(\left|\underline{x}_{2}-\underline{x}_{0}\right|\right) \\
1
\end{array}\right] ;
$$

performing the multiplication yields:

$$
\begin{aligned}
& \lambda_{1}=\frac{1}{2 \gamma\left(\left|\underline{x}_{1}-\underline{x}_{2}\right|\right)}\left[-\gamma\left(\left|\underline{x}_{1}-\underline{x}_{0}\right|\right)+\gamma\left(\left|\underline{x}_{2}-\underline{x}_{0}\right|\right)+\mu_{0} \gamma\left(\left|\underline{x}_{1}-\underline{x}_{2}\right|\right)\right] \\
& \lambda_{2}=\frac{1}{2 \gamma\left(\left|\underline{x}_{1}-\underline{x}_{2}\right|\right)}\left[\gamma\left(\left|\underline{x}_{1}-\underline{x}_{0}\right|\right)-\gamma\left(\left|\underline{x}_{2}-\underline{x}_{0}\right|\right)+\mu_{0} \gamma\left(\left|\underline{x}_{1}-\underline{x}_{2}\right|\right)\right] \\
& \mu_{0}=\frac{1}{2}\left[\gamma\left(\left|\underline{x}_{1}-\underline{x}_{0}\right|\right)+\gamma\left(\left|\underline{x}_{2}-\underline{x}_{0}\right|\right)-\gamma^{2}\left(\left|\underline{x}_{1}-\underline{x}_{2}\right|\right)\right] .
\end{aligned}
$$

Note that the variogram for all pairs of points enters into the calculation of each $\lambda$; this prevents adjacent points containing redundant information from being too heavily weighted.

The minimum or kriging variance, $\sigma_{K}^{2}$, can be calculated from $\sigma^{2}$ and the system of Equations (A-2) as follows. Recall that

$$
\sigma^{2}=2 \sum_{i=1}^{N} \lambda_{i} \gamma\left(\left|x_{i}-x_{0}\right|\right)-\sum_{i} \sum_{j} \lambda_{i} \lambda_{j} \gamma\left(\left|x_{i}-x_{j}\right|\right) .
$$

For each $i$, from the set of Equations $(A-2)$,

$$
\sum_{j=1}^{N} \lambda_{j} \gamma\left(\left|\underline{x}_{i}-\underline{x}_{j}\right|\right)=\gamma\left(\left|\underline{x}_{i}-\underline{x}_{0}\right|\right)-\sum_{\ell} \mu_{\ell} f^{\ell}\left(\underline{x}_{0}\right) .
$$

Making this substitution in Equation (A-3) yields

$$
\sigma_{K}^{2}=\sum_{i=1}^{N} \lambda_{i} \gamma\left(\left|\underline{x}_{i}-\underline{x}_{0}\right|\right)-\sum_{\ell} \mu_{\ell} f^{\ell}\left(\underline{x}_{0}\right) \text {. }
$$




\section{Jackknife Statistic}

Recall that the criterion for evaluating the kriging model is based on

$$
\rho=\frac{E\left[\sum_{i} Z\left(\lambda_{i}\right)^{2}\right]}{E \sum_{i} \hat{\sigma} j^{2}},
$$

which should be close to 1 . It is estimated by the statistic

$$
r=\frac{\left[\sum_{i} z\left(\lambda_{i}\right)^{2}\right]}{\sum_{i} \hat{\sigma}_{i}^{2}} ;
$$

however $r$ is a biased estimator of $\rho$. An improved estimator can be obtained by splitting the data into two groups, $I_{1}$ and $I_{2}$ : anc computins

$$
r_{j}=\frac{\sum_{i \in I_{j}} Z\left(\lambda_{j}\right)^{2}}{\sum_{i \in I_{j}} \hat{\sigma}_{i}^{2}}, j=1,2,
$$

and forming the jackknife statistic,

$$
\hat{\rho}=2 r-\frac{n_{1} r_{1}+n_{2} r_{2}}{n_{1}+n_{2}} \text {. }
$$




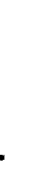


No. of

Copies

offsite

Dr. Dale E. Baker

Pennsylvania State University

Department of Agronomy

221 Tyson Building

University Park, PA 16802

M. G. Barnes

Desert Research Institute

$U$. of Nevada System

4582 Maryland Parkway

Las Vegas, NV 89109

J. W. Bartlett

TASC

6 Jacob Way

Reading, MA 01867

A. A. Churm

DOE Chicago Patent Group

9880 South Cass Avenue

Argonne, IL 60439

Dr. Pierre Delfiner

Ecole de Mines de Paris

Centre de Geostatistics

35 Rue Saint-Honoré

77305 Fontainebleau, France

P. B. Dunaway

Nevada Operations Office

U.S. DOE

P.0. Box 14100

Las Vegas, NV 89114

Dr. Andre Journel

Department of Applied Earth Sciences

Stanford University

Stanford, CA 94305 


\section{DISTRIBUTION (Cont'd.)}

No. of

Copies

Offsite

R. R. Kinnison

Environmental Monitoring and Support Laboratory

Environmental Protection Agency

P.0. Box 15027

Las Vegas, NV 89114

Dr. Richard M. Lessler

Bechtel National, Inc.

Fifty Beale Street

P.0. Box 3965

San Francisco, CA 94119

J. Malaro

NRC High Level Nuclear Waste Branch

Washington, DC 20555

J. Martin

NRC Division of Nuclear Waste

Management

Washington, DC 20555

Dr. Lincoln Moses

Energy Information Administration

Department of Energy

Washington, DC 20461

J. Russell

EPA Office of Radiation Programs

Technical Assessment Division (AW-559)

Washington, DC 20460

Dr. Edward Tang

Department of Civil Engineering

Stanford University

Stanford, CA 94305

334 DOE Technical Information Center

$\varepsilon$ Battelle Memorial Institute

office of Nuclear llaste Isolation

505 King Avenue

Columbus, Ohio

B. Rawles

H.C. Burkholder

Distr.-2 
DISTRIBUTION (Cont'd.)

No. of

Copies

Offsite

Office of Nuclear Waste Isolation (Cont'd.)

W. M. Hewitt W.A. Cariviener

M. Kehnemuyi N.E. Carter

R. B. Laughon R.E. Heineman

2 Savannah River Ecology Laboratory

Drawer E

Aiken, SC 29801

J. E. Pinder

M. H. Smith

6 Los Alamos Scientific Laboratory University of California

P.0. Box 1663

Los Alamos, NM 87545
E. S. Essington
T. E. Hakonson
R. K. Lohrding
G. T. Tietjen
G. White

2 DOE Office of Health and Environmental Programs Washington, DC 20545

W. 0 . Forster

R. L. Watters

4 DOE Division of Waste Management Washington, DC 20545
C. R. Cooley
W. Eister
C. A. Heath
G. K. Oertel

Onsite

5 Richland Operations Office
R. B. Goranson
H. E. Ransom
J. Schreiber
M. W. Shupe
M. G. White

Distr. -3 


\section{DISTRIBUTION (Cont'd.)}

No. of

Copies

7 Rockwell

R. C. Arnett

R. G. Baca

R. A. DeJu

L. Jensen

R. K. Ledgerwood

P. E. Long

C. 0. Murphy

25 Pacific Northwest Laboratory

T. W. Ambrose

A. Brandstetter

R. E. Brown

D. B. Carr

D. B. Cearlock

L. L. Eberhardt

C. E. Elderkin

D. R. Friedrichs

J. J. Fuquay

R. 0. Gilbert

W. C. Hanson

M. A. Harwell

R. L. Hooper

V. M. Lee

R. C. Liikala

R. W. Nelson

W. L. Nicholson

A. M. Platt

J. R. Raymond

A. E. Reisenauer

J. V. Robinson

J. C. Simpson

J. Thomas

L. D. Williams

B. E. Vaughan

Technical Information 5

Publishing Coordination 2 